\title{
Occurrence of UVA- and UVB-absorbing compounds in 152 species (206 strains) of marine microalgae
}

\author{
S. W. Jeffrey ${ }^{1, *}$, H. S. MacTavish ${ }^{1,2,3}$, W. C. Dunlap ${ }^{4}$, M. Vesk ${ }^{2}$, K. Groenewoud ${ }^{1,2}$ \\ ${ }^{1}$ CSIRO Division of Marine Research, GPO Box 1538, Hobart, Tasmania 7001, Australia \\ ${ }^{2}$ Electron Microscope Unit, Sydney University, New South Wales 2006, Australia \\ ${ }^{3}$ Department of Agricultural Science, University of Tasmania, Tasmania 7001, Australia \\ ${ }^{4}$ Australian Institute of Marine Science, PMB 3, Townsville, Queensland, 4810, Australia
}

\begin{abstract}
Marine microalgae (152 species, 206 strains) from 12 classes were examined for the presence of UVA- and UVB-absorbing compounds. Cultures were grown under white fluorescent light without supplementary UVA or UVB radiation and were extracted after harvest in tetrahydrofuran:methanol $(20: 80, \mathrm{v} / \mathrm{v})$. Ratios of UV absorbance (280 to $390 \mathrm{~nm}$ ) to chlorophyll a (chl a) (665 nm) obtained by spectrophotometry ranged from 0.18 to 6.75 . Three groups of species were distinguished: those with low UV:chl a ratios 10.18 to 0.9 , diatoms, green algae, cyanophytes, euglenophytes, eustigmatophytes, rhodophytes, some dinoflagellates, some prymnesiophytes), those with intermediate ratios (0.9 to 1.4 , chrysophytes, some prasinophytes, some prymnesiophytes) and those with very high ratios (1.4 to 6.75, surface bloom-forming dinoflagellates, cryptomonads, prymnesiophytes and raphidophytes). UV-absorbing pigments varied across species of the same algal class and strains of the same species. HPLC analysis of extracts of 5 species (1 diatom, 2 bloom-forming raphidophytes and 2 bloomforming dinoflagellates) showed suites of mycosporine-like amino acids in 4 of them, which included mycosporine-glycine, asterina-330, shinorine, porphyra-334 and palythine. The dinoflagellate Gymnodinium catenatum also contained major quantities of unknown UV-absorbing compounds.
\end{abstract}

KEY WORDS: Ultraviolet radiation - Microalgae - Dinoflagellates - Cryptomonads - Prymnesiophytes · Raphidophytes Mycosporine-like amino acids Bloom-forming species. Gymnodinium catenatum

\section{INTRODUCTION}

Ultraviolet- $B$ radiation (UVB) reaching the earth's surface is increasing as a result of anthropomorphic damage to the stratospheric ozone layer. First detected over the Antarctic by Farman et al. (1985), seasonal ozone depletion has now also been documented above the Arctic and mid-latitudes (north and south) (e.g. Frederick \& Snell 1988, Roy et al. 1990, Stolarski et al. 1992, Kerr \& McElroy 1993). Of immediate concern to this expanding global problem are the potential threats to biological ecosystems (Calkins 1982). UVB ( 280 to $320 \mathrm{~nm}$ ) has a high energy level per photon and is effectively absorbed by nucleic acids (affecting the

·E-mail: s.w.jeffrey@marine.csiro.au genome), proteins and pigments. Not only are terrestrial ecosystems at risk (Caldwell 1981, Bornman 1989, Bornman \& Teramura 1993, Rozema et al. 1997), with evidence that UVB affects plant morphology, biomass production and photosynthesis, but marine ecosystems may also be threatened (Worrest 1982, El-Sayed \& Stephens 1992).

Even before the recent ozone concerns were apparent, it was known from direct measurements (Jerlov 1950,1976 ) and from inhibition studies of in situ phytoplankton productivity (Steeman Nielsen 1964, Jitts et al. 1976, Lorenzen 1979, Smith et al. 1980, Worrest et al. 1980) that, in aquatic systems, UVB penetrates to ecologically significant depths (up to $20 \mathrm{~m}$ ). More recent in situ measurements by Smith et al. (1992) have shown that UV penetrates to $70 \mathrm{~m}$ depth in oligotrophic waters, and that direct inhibition of phyto- 
plankton productivity in Antarctic waters ( 0 to $12 \%$ ) is correlated with ozone depletion (Worrest \& Häder 1997).

Recent research has highlighted a variety of UVB damage effects in phytoplankton, expanding on early concepts (Halldal 1967). These include damage to nuclear DNA (dimer formation, Karentz et al. 1991a, Buma et al. 1995, 1996) with consequent inhibition of cell growth rates, inhibition of photosynthesis with lesions in the Photosystem II-D1 reaction centre protein (Jordan et al. 1991), loss of, and changes to, the key photosynthetic enzyme, ribulose bis-phosphate carboxylase (Rubisco) (Strid et al. 1990, Lesser et al. 1994, 1996, Wilson et al. 1995, Lesser 1996), decreased nitrogen uptake, metabolism and protein synthesis (Döhler et al. 1987, 1991, Goes et al. 1995, Döhler 1996), and loss of photo-orientation and motility in dinoflagellates, diatoms and other species (e.g. Häder \& Häder 1988, Ekelund 1990, Donkor et al. 1993, Nielsen \& Ekelund 1993, Sundbäck et al. 1996, 1997). The severity of these effects depends on the length and intensity of UVB exposure, the nutrient status of the cells, individual species responses, and supplementary radiation involved in repair processes (e.g. photosynthetically active radiation (PAR), UVA or red/blue radiation)

To counteract harmful UV effects, terrestrial and aquatic plants have evolved UV-protective, anti-oxidant, avoidance and repair mechanisms to aid survival (see Dunlap \& Shick 1998). These include rapid DNA repair mechanisms (Sancar \& Sancar 1988, Buma et al. 1995), avoidance reactions (e.g. photo-orientation in diatoms and dinoflagellates, see above), protective sheaths in cyanobacteria and protective cell walls in freshwater green microscopic algae (Garcia-Pichel \& Castenholz 1991, Xiong et al. 1997), and synthesis of cytoplasmic protective pigments with a UV-absorbing sunscreen function. These last compounds include flavonoids in higher plants (Caldwell 1981) and mycosporine-like amino acids (MAAs) in marine biota (Nakamura et al. 1982, reviewed by Dunlap \& Shick 1998).

UV-absorbing MAAs have been found in marine plants and animals from Antarctic regions to the tropics (Tsujino et al. 1980, Nakamura et al. 1981, 1982, Dunlap \& Chalker 1986, Dunlap et al. 1986, 1989, Karentz et al. 1991b, Shick et al. 1991, 1992, 1995, Stochaj et al. 1994, Dionisio-Sese et al. 1997, Dunlap \& Shick 1998). MAA-like compounds were studied in a small number of microalgae-the 4 dinoflagellates Noctiluca miliaris (Balch \& Haxo 1984), Alexandrium excavatum (Carreto et al. 1990), Prorocentrum micans and Gonyaulax polyedra (Vernet et al. 1989), colonial strains of the prymnesiophyte (=haptophyte) Phaeocystis pouchetii (Marchant et al. 1991), Antarctic diatom mats (Karentz et al. 1991b), a number of Antarctic diatom cultures (Helbling et al. 1996, Riegger \& Robinson 1997), and the tropical cyanobacterium Trichodesmium sp. (Shibata 1969). Some cyanobacteria are known to have the UV-absorbing extracellular sheath pigment scytonemin (Garcia-Pichel \& Castenholz 1991), whereas in freshwater green algae sporopollenin in cell walls acts as a UV absorber (Xiong et al. 1997). MAAs have also been found in 20 strains of cyanobacteria (13 genera) isolated from habitats receiving high natural solar radiation (GarciaPichel \& Castenholz 1993), 20 isolates of Microcoleus (cyanobacteria) (Karsten \& Garcia-Pichel 1996), and in a community of halophilic cyanobacteria (Oren 1997).

UV-absorbing compounds have long been suggested to protect cells from UV damage (see Shibata 1969, Dunlap et al. 1986, Vernet et al. 1989, Carreto et al. 1990, Helbling et al. 1996), but experimental evidence was unclear until recently. Adams \& Shick (1996) provided the first direct experimental evidence for the UV-photoprotective function of MAAs in the eggs of sea urchins during reproductive development. More recently Neale et al. (1998) have shown that UV sunscreens (MAAs) in the dinoflagellate Gymnodinium sanguineum clearly protect against UV inhibition of photosynthesis.

In the present work we investigated the occurrence of UV-absorbing compounds in 152 species $(=206$ strains) of cultured marine microalgae from 12 classes, a greater variety than had previously been examined, in order to gain further understanding of MAA distribution as a possible protective mechanism against UV radiation in the phytoplankton. The strains came from our extensive bank of cultured microalgae in the CSIRO Algal Culture Collection and were isolated from a variety of tropical, temperate and polar habitats, both in Australia and overseas (Jeffrey 1980, Jeffrey \& LeRoi 1997. CSIRO 1998). Particular attention. was given to surface bloom-forming species that might normally live in a UV-rich environment (dinoflagellates, prymnesiophytes, cryptomonads and raphidophytes). In addition, we examined natural surface phytoplankton samples, containing mainly dinoflagellates and diatoms, that had received ambient solar radiation.

\section{MATERIALS AND METHODS}

Algal cultures. Cultures (152 species, 206 strains) from 12 algal classes were obtained from the CSIRO Algal Culture Collection (Jeffrey 1980, CSIRO 1998). Full details including dates of isolation and deposition into the Collection are given in CSIRO (1998).

The cultures were grown according to Jeffrey \& LeRoi (1997), and were maintained in stationary $125 \mathrm{ml}$ 
pyrex Erlenmeyer flasks containing $75 \mathrm{ml}$ medium. Names of species examined, CSIRO culture code numbers, culture media and growth temperatures are listed in Table 1 Growth temperatures were 25 to $27^{\circ} \mathrm{C}$ for tropical species, 12 to $17.5^{\circ} \mathrm{C}$ for temperate species and $5^{\circ} \mathrm{C}$ for Antarctic species. Photosynthetically active radiation was provided by banks of Philip's Daylight fluorescent tubes (TL20W47 de Luxe), beneath glass shelves supporting the culture flasks. Philip's Daylight fluorescent lamps produce a more uniform spectrum than cool white lamps and therefore simulate the natural daylight spectrum more closely (see Behrenfeld et al. 1994). Dinoflagellates received overhead illumination. No supplementary UV radiation was provided. Light irradiances (12 h light:12 h dark cycles) were generally 70 to $80 \mu \mathrm{E} \mathrm{m} \mathrm{m}^{-2} \mathrm{~s}^{-1}$, or $20 \mu \mathrm{E} \mathrm{m} \mathrm{m}^{-2} \mathrm{~s}^{-1}$ for picoplanktonic cyanobacteria isolated from the deep euphotic zone. Light measurements were obtained in the culture flasks with a Biospherical Optics light meter before algal innoculation.

Field samples. Natural phytoplankton field samples having received natural incident radiation were collected with a $33 \mu \mathrm{m}$ mesh plankton net from a depth of $1 \mathrm{~m}$ at the CSIRO Marine Laboratories wharf station (Derwent River Estuary, water depth 5 to $6 \mathrm{~m}$ ). Dates of collection were 11 March 1991, 16 May 1991, 22 July 1992, and 15 September 1992. This station is usually rich in dinoflagellates (Ceratium, Dinophysis, Gymnodinium spp.) alternating with diatoms (mainly Chaetoceros spp., Hallegraeff et al. 1989). Each sample was examined microscopically to determine major cell types before extraction. The samples were extracted by the same techniques as the cultured samples, described below.

Culture harvest and pigment extraction for spectrophotometry. Cultured microalgae, which had been maintained in the absence of supplementary UV radiation for between 2 and $35 \mathrm{yr}$, were harvested in mid to late log phase. Before extraction each culture was checked microscopically to ensure good cell morphology. Duplicate $10 \mathrm{ml}$ samples were withdrawn from each culture, usually 2 to $4 \mathrm{~h}$ into the light cycle, and cells were harvested by centrifugation at $2000 \mathrm{~g}$ for 3 to $5 \mathrm{~min}$. The pellet was extracted with $1 \mathrm{ml}$ cold $\left(5^{\circ} \mathrm{C}\right)$ tetrahydrofuran: methanol $(20: 80, v / v)$, a solvent mixture which provided maximum extraction efficiency for both MAAs and lipophilic pigments (Chalker \& Dunlap 1982, Dunlap et al. 1986). Cells were chilled in an ice bath during extraction and were sonicated for $60 \mathrm{~s}$ in a sonicator bath, using a Bransonic Model 52 sonicator. The solvent mixture extracted both UVabsorbing mycosporine amino acids and photosynthetic pigments from most algal cells, leaving a colourless pellet. Some of the chlorophytes with tough cellulose walls were extremely difficult to extract. In these cases cell pellets were frozen in a small volume of distilled water before solvent extraction, to weaken the cell walls for enhanced extraction efficiency. After centrifugation in a Sorvall refrigerated centrifuge, the absorption spectrum of the supernatant was taken between 190 and $700 \mathrm{~nm}$ with a Shimadzu UV-240 recording spectrophotometer, the baseline of which had been previously set to zero. No drift was encountered. The relative proportion of UV absorbance to chl a was calculated as the ratio of absorbance intensity at the UV maxima between 280 and $390 \mathrm{~nm}$ to that of chlorophyll a at $665 \mathrm{~nm}$. All extraction procedures were carried out in a darkened fume cupboard, to minimize photo-oxidative pigment breakdown of chlorophylls and carotenoids during analysis.

Extraction of samples for HPLC analysis of mycosporine amino acids. Extracts of 5 species of microalgae were examined by HPLC to see if they contained UV-absorbing compounds similar to the MAAs found in other marine plants and animals. Cultures examined were the diatom Chaetoceros affinis, the raphidophytes Heterosigma carterae and Fibrocapsa sp., and the dinoflagellates Woloszynskia sp. and Gymnodinium catenatum. For each species $450 \mathrm{ml}$ late log phase cultures were used for these extractions. Cultures were centrifuged in a Sorvall refrigerated centrifuge at $5000 \mathrm{~g}$ for $5 \mathrm{~min}$. The cell pellets were extracted with 1 to $2 \mathrm{ml}$ of cold $\left(5^{\circ} \mathrm{C}\right)$ tetrahydrofuran:methanol $(20: 80, \mathrm{v} / \mathrm{v})$ in an ice bath, using a Braun Labsonic Model 1510 sonicator with a $4 \mathrm{~mm}$ needle probe $(1 \mathrm{~min})$, and left for $30 \mathrm{~min}$ at $5^{\circ} \mathrm{C}$ to fully extract. MAAs are stable in wet methanol under the following conditions: 1 to $2 \mathrm{~d}$ at room temperature (e.g. $20^{\circ} \mathrm{C}$ ), $1 \mathrm{wk}$ at $5^{\circ} \mathrm{C}, 2$ to $3 \mathrm{wk}$ at $-20^{\circ} \mathrm{C}$ and $2 \mathrm{mo}$ at $-80^{\circ} \mathrm{C}$. Since stability rapidly decreases with storage temperatures greater than $30^{\circ} \mathrm{C}$ care was taken to keep temperatures around $5^{\circ} \mathrm{C}$ during experimental treatments. When dry, samples are stable at room temperature for several months.

After centrifugation of the combined extracts (about 5 to $6 \mathrm{ml}$ ), a small aliquot $(0.1$ to $0.2 \mathrm{ml})$ was diluted for spectrophotometry, and equal volumes of the remaining extract were placed in 4 Eppendorf tubes and evaporated in a Savant evaporator for several hours at ambient temperature $(0.9$ to $1.5 \mathrm{ml})$. Samples could be left overnight at $-20^{\circ} \mathrm{C}$ if evaporation was not complete, and evaporations were then completed the following day. The quadruplicate tubes of the lyophilized algal extracts of each species were then dispatched to Dr W. Dunlap at the Australian Institute for Marine Science (AIMS) for HPLC analysis. MAAs are stable under these conditions (see above).

HPLC analyses. Analyses of MAAs were performed according to published procedures (Dunlap \& Chalker 1986, Dunlap et al. 1989, Karentz et al. 1991b, Stochaj 
Table 1. UV-absorption characteristics of tetrabydrofuran:methanol (20:80, v/v) extracts of 152 species (206 strains) of cultured unicellular manne algae. Ratios of UV absorption to chl a absorption are listed with UV maxima in parentheses. For geographic origin of strains see the CSIRO Algal Culture Collection Strain List (CSIRO 1998)

\begin{tabular}{|c|c|c|c|c|c|}
\hline \multirow[t]{2}{*}{ Class and species } & \multirow{2}{*}{$\begin{array}{c}\text { CSIRO } \\
\text { culture code }\end{array}$} & \multirow{2}{*}{$\begin{array}{l}\text { Culture } \\
\text { medium }^{\mathrm{a}}\end{array}$} & \multirow{2}{*}{$\begin{array}{l}\text { Growth } \\
\text { temp. }\left({ }^{\circ} \mathrm{C}\right)\end{array}$} & \multicolumn{2}{|c|}{ Abs. ratio of major UV peaks:chl a $(665 \mathrm{~nm})$} \\
\hline & & & & $280-320 \mathrm{~nm}$ & $320-340 \mathrm{~nm} \quad 340-390 \mathrm{~nm}$ \\
\hline \multicolumn{6}{|l|}{ BACILLARIOPHYCEAE } \\
\hline \multicolumn{6}{|l|}{ Centrales } \\
\hline Chaetoceros affinis Lauder & CS-78 & $\mathrm{G}_{2}$ & 17.5 & & $0.74(337.9)$ \\
\hline Chaetoceros caicitrans (Paulsen) Takano & $\mathrm{CS}-178$ & $\mathrm{fE}_{2}$ & 17.5 & & $0.64(337)$ \\
\hline Chaetoceros didymus Ehrenberg & $\mathrm{CS}-2$ & $\mathrm{f}_{2}$ & 17.5 & & $0.80(337)$ \\
\hline Chaetoceros muelleri Lemmermann & CS -176 & $\mathrm{f}_{2}$ & 17.5 & & $0.74(337.5)$ \\
\hline Chaetoceros cf. mitra (Bail.) Cleve & CS-70 & G & 17.5 & & $0.48(337.9)$ \\
\hline Chaetoceros cf. radians Schutt & CS-68 & G & 17.5 & & $0.81(337.3)$ \\
\hline Chaetoceros socialis Lauder & $\mathrm{CS}-236$ & G & 17.5 & & $0.83(337.1)$ \\
\hline Coscinodiscus cf. wailesi Gran. et Angst. & CS-238 & $\mathrm{f}_{2}$ & 17.5 & & $0.52(338.1)$ \\
\hline Coscinodiscus sp. & CS-151 & $\mathrm{f}_{2}$ & 17.5 & & $0.69(338)$ \\
\hline Detonula pumila Schutt & CS-103 & $\mathrm{f}_{2}$ & 17.5 & & $0.78(337.1)$ \\
\hline Ditylum brightwellii ( $\mathrm{T}$. West) Grunow & CS-74 & $\mathrm{G}$ & 17.5 & & $0.49(337.3)$ \\
\hline Ditylum brightwellii (T West) Grunow & $\mathrm{CS}-131$ & $\mathrm{f}_{2}$ & 17.5 & & $0.72(337.9)$ \\
\hline $\begin{array}{l}\text { Extubocellulus spinifer (Hargraves et } \\
\text { Guillard) Has.e, Von Stosch et Syvertsen }\end{array}$ & CS-136 & $\mathrm{G}_{2}$ & 17.5 & & $0.82(337.9)$ \\
\hline Lauderia annulata Cleve & CS-30 & G & 17.5 & & $0.71(337.5)$ \\
\hline $\begin{array}{l}\text { Minutocellus polymorphus (Hargraves et } \\
\text { Guillard) Has.e, Von Stosch et Syvertsen }\end{array}$ & CS-3 & $\mathrm{f}_{2}$ & 17.5 & & $0.74(337.7)$ \\
\hline Odontella aurita (Lyngbye) de Brebisson & CS-19 & $\mathrm{f}_{2}$ & 17.5 & \multirow{19}{*}{$0.54(300.9)$} & $0.61(337.7)$ \\
\hline Odontella mobiliensis (Bail.) Grunow & CS-82 & $\mathrm{f}_{2}$ & 17.5 & & $0.71(336.9)$ \\
\hline Odontella mobiliensis (Bail.) Grunow & CS-133 & $\mathrm{f}_{2}$ & 17.5 & & $0.57(336.3)$ \\
\hline Rhizosolenia setigera Brightwell & CS-62 & $\mathfrak{f}_{2}$ & 17.5 & & $0.74(337.5)$ \\
\hline Skeletonema pseudocostatum Medlin & $\mathrm{CS}-76$ & $\mathrm{G}_{2}$ & 17.5 & & $0.68(336.7)$ \\
\hline Skeletonema costatum (Greville) Cleve & CS-167 & $\mathrm{G}_{2}$ & 17.5 & & $0.70(337)$ \\
\hline Skeletonema costatum (Greville) Cleve & CS-181 & $\mathrm{f}_{2}$ & 17.5 & & $0.72(336.7)$ \\
\hline Stephanopyxis iurris (Greville) Ralfs in Pritchard & $\mathrm{CS}-31$ & G & 17.5 & & $0.82(337.5)$ \\
\hline Stephanopyxis iuris (Greville) Ralfs in Pritchard & CS -100 & G & 17.5 & & $0.83(336.9)$ \\
\hline Streptotheca tamesis Shrubsole & CS-81 & $\mathrm{G}_{2}$ & 17.5 & & $0.77(338.3)$ \\
\hline Streptotheca tamesis Shrubsole & $\mathrm{CS}-130$ & $\mathrm{G}_{5}$ & 17.5 & & $0.93(337.7)$ \\
\hline Thalassiosira eccentrica (Ehrenb.) Cleve & CS-148 & $\mathrm{f}_{2}$ & 27 & & $0.66(338.1)$ \\
\hline Thalassiosira oceanica Hasle & CS-67 & $\mathrm{f}_{2}$ & 17.5 & & $0.55(338.1)$ \\
\hline Thalassiosira pseudonana (Hust.) Hasle et Heimdal & CS-20 & $\mathrm{f}_{2}$ & 17.5 & & $0.64(337.3)$ \\
\hline Thalassiosira pseudonana (Hust.) Hasle et Heimdal & CS-173 & $\mathrm{fE}_{2}$ & 17.5 & & $0.68(336.7)$ \\
\hline Thalassiosira rotula Meunier & CS-32 & G & 17.5 & & $0.58(338.7)$ \\
\hline Thalassiosira rotula Meunier & $\mathrm{CS}-77$ & $\mathrm{G}_{2}$ & 17.5 & & $0.79(336.7)$ \\
\hline Thalassiosira rotula Meunier & CS-102 & $\mathrm{G}_{2}$ & 17.5 & & $0.72(337.7)$ \\
\hline Thalassiosira stellaris Hasle et Guillard & CS-16 & G & 17.5 & & $0.64(337.7)$ \\
\hline \multicolumn{6}{|l|}{ Pennales } \\
\hline Amphiprora hyalina Eulenstein & CS -28 & $\mathrm{f}_{2}$ & 17.5 & & $0.65(337.7)$ \\
\hline Amphora sp. & CS-10 & $\mathrm{f}_{2}$ & 17.5 & & $0.63(337.9)$ \\
\hline Amphora sp. & CS-361 & $\mathrm{fE}_{2}$ & 27 & & $0.66(337.1)$ \\
\hline Asterionella glacialis Castracane & CS-90 & $\mathrm{f}_{2}$ & 17.5 & & $0.75(337.3)$ \\
\hline Asterionella glacialis Castracane & CS-135 & $\mathrm{f}_{2}$ & 17.5 & & $0.66(338.1)$ \\
\hline Cylindrotheca fusiformis Reimann et Lewin & CS-13 & $\mathrm{f}_{2}$ & 17.5 & & $0.75(337.5)$ \\
\hline Delphineis sp. & CS-12 & $\mathrm{f}_{2}$ & 17.5 & & $0.77(338.5)$ \\
\hline Fragilaria pinnata Ehrenb. & CS-121 & $f_{2}$ & 27 & & $0.68(338.6)$ \\
\hline Grammatophora oceanica Ehrenb. & CS-84 & $\mathrm{f}_{2}$ & 17.5 & & $0.57(338.5)$ \\
\hline Haslea ostrearia Bory & $\mathrm{CS}-250$ & $\mathrm{f}_{2}$ & 15 & & $0.88(337.1)$ \\
\hline Navicula jeffreyi Hallegraeff et Burford & CS-46 & $\mathrm{f}_{2}$ & 17.5 & & $0.85(337.1)$ \\
\hline Nitzschia cf. bilobata W. Smith & $C S-47$ & $\mathrm{f}_{2}$ & 17.5 & & $0.76(337.9)$ \\
\hline Nitzschia closterium (Ehrenb.) W. Smith & $\mathrm{CS}-1$ & $f_{2}$ & 17.5 & & $0.18(338.3)$ \\
\hline Nitzschia closterium (Ehrenb.) W. Smith & CS-5 & $\mathrm{f}_{2}$ & 17.5 & & $0.72(337.9)$ \\
\hline Nitzschia closterium (Ehrenb.) W. Smith & CS-114 & $f_{2}$ & 27 & & $0.72(337.3)$ \\
\hline Nitzschia closterium (Ehrenb.) W. Smith & CS-111 & $\mathrm{f}_{2}$ & 27 & & $0.85(337.3)$ \\
\hline Nitzschia cf. frustulum (Kutz.) Grun. & CS-258 & $\mathrm{G}_{2}$ & 27 & & $0.86(336.7)$ \\
\hline Nitzschia cf. frustulum (Kutz.) Grun. & CS-115 & $\mathrm{f}_{2}$ & 27 & & $0.75(337.3)$ \\
\hline Nitzschia cf. constricta (Greg.) Grun. & CS-106 & $\mathrm{G}$ & 27 & & $0.86(337.1)$ \\
\hline Nitzschia sp. (Prydz Bay, Antarctica) & & $\mathrm{f}_{2}$ & 5 & & $1.22(336.9)$ \\
\hline Phaeodactylum tricornutum Bohlin & CS-29 & $f_{2}$ & 17.5 & & $0.75(333.6)$ \\
\hline Thalassionema nitzschioides Hustedt & CS-146 & $\mathrm{f}_{2}$ & 27 & & $0.86(337.8)$ \\
\hline Thalassiothrix heteromorpha Karsten & CS-132 & $\mathrm{f}_{2}$ & 17.5 & & $1.02(337.7)$ \\
\hline
\end{tabular}


Table 1 (continued)

\begin{tabular}{|c|c|c|c|c|c|c|}
\hline \multirow[t]{2}{*}{ Class and species } & \multirow{2}{*}{$\begin{array}{l}\text { CSIRO } \\
\text { culture code }\end{array}$} & \multirow{2}{*}{$\begin{array}{l}\text { Culture } \\
\text { medium }^{\mathrm{a}}\end{array}$} & \multirow{2}{*}{$\begin{array}{l}\text { Growth } \\
\text { temp. }\left({ }^{\circ} \mathrm{C}\right)\end{array}$} & \multicolumn{3}{|c|}{ Abs. ratio of major UV peaks:chl a $(665 \mathrm{~nm})$} \\
\hline & & & & $280-320 \mathrm{~nm}$ & $320-340 \mathrm{~nm}$ & $340-390 \mathrm{~nm}$ \\
\hline \multicolumn{7}{|l|}{ CHLOROPHYCEAE } \\
\hline Chlamydomonas reinhardii Dangeard & CS-51 & $\mathrm{MBL} / \mathrm{NB}_{2}$ & 17.5 & $0.42(295.2)$ & $0.63(338.7)$ & \\
\hline Chlorella protothecoides Krüger & CS -41 & $\mathrm{MBL} / \mathrm{NB}_{2}$ & 17.5 & & $0.62(337.5)$ & \\
\hline Chlorella vulgaris Beijerinck & $\mathrm{CS}-42$ & $\mathrm{MBL} / \mathrm{NB}_{2}$ & 17.5 & & $0.65(338)$ & \\
\hline Chlorella sp. & CS-122 & $\mathrm{D}$ & 25 & & $0.73(339.5)$ & \\
\hline Chlorella-like & CS-195 & $\mathrm{fE}_{2}$ & 25 & & $0.78(339.3)$ & \\
\hline Chlorella-like & CS- 247 & $\mathrm{G}_{2}$ & 17.5 & & $0.80(338.6)$ & \\
\hline Chlorella-like & CS-248 & $\mathrm{G}_{2}$ & 17.5 & & $0.87(330.9)$ & \\
\hline Dunaliella salina (green form) Teodoresco & CS-265 & $\mathrm{f}_{2}$ & 25 & & $0.71(339.3)$ & \\
\hline Dunaliella salina (orange form) Teodoresco & CS-265 & $f_{2}$ & 30 & & $1.35(340.4)$ & \\
\hline Dunaliella tertiolecta Butcher & CS-175 & $\mathrm{f}_{2}$ & 17.5 & $0.34(296.7)$ & $0.58(338.9)$ & \\
\hline Dunaliella sp. (Burton Lake, Antarctica) & & $\mathrm{f}_{2}$ & 5 & & $0.63(339.8)$ & \\
\hline Dunaliella sp. (Ace Lake, Antarctica) & & $\mathrm{f}_{2}$ & 5 & & $0.66(338.1)$ & \\
\hline Nannochloris atomus Butcher & CS-183 & $f_{2}$ & 17.5 & & $0.56(338.5)$ & \\
\hline Nannochloris atomus Butcher & CS-184 & $\mathrm{f}_{2}$ & 17.5 & & $0.56(338.8)$ & \\
\hline Stichococcus sp. & $\mathrm{CS}-92$ & $\mathrm{f}_{2}$ & 17.5 & & $0.71(338.2)$ & \\
\hline \multicolumn{7}{|l|}{ CHRYSOPHYCEAE } \\
\hline Pelagococcus subviridis Norris & CS -58 & $\mathrm{f}_{2}$ & 17.5 & & $1.08(337.9)$ & \\
\hline Pelagococcus subviridis Norris & CS-99 & $\mathrm{f}_{2}$ & 17.5 & & $1.06(337.3)$ & \\
\hline \multicolumn{7}{|l|}{ CRYPTOPHYCEAE } \\
\hline $\begin{array}{l}\text { Rhodomonas salina (Wislouch) Hill } \\
\text { et Wetherbee }\end{array}$ & $\mathrm{CS}-24$ & fE & 17.5 & & $0.66(339.1)$ & \\
\hline $\begin{array}{l}\text { Rhodomonas salina (Wislouch) Hill } \\
\text { et Wetherbee }\end{array}$ & CS-174 & fE & 17.5 & $0.47(288.3)$ & $0.58(339.4)$ & \\
\hline Chroomonas placoidea Butcher & CS-200 & $\mathrm{G}$ & 17.5 & & $0.95(335)$ & \\
\hline $\begin{array}{l}\text { Rhodomonas maculata Butcher ex Hill } \\
\text { et Wetherbee }\end{array}$ & CS-85 & $\mathrm{fE}$ & 17.5 & & $0.68(339.3)$ & \\
\hline Rhodomonas baltica Karsten & CS-201 & $\mathrm{G}$ & 17.5 & $2.96(284.8)$ & $0.73(337.2)$ & \\
\hline STX-157 (Chroomonas sp.?) & $\mathrm{CS}-48$ & $\mathrm{fE}$ & 17.5 & $2.07(280.0)$ & $0.68(337.9)$ & \\
\hline Geminigera cryophila (Taylor et Lee) Hill & CS-138 & $\mathrm{f}_{2}$ & 5 & & $0.63(339)$ & \\
\hline Chroomonas sp. (MB-3) & CS-204 & $\mathrm{G}$ & 17.5 & $2.44(283.5)$ & $0.67(337.9)$ & \\
\hline Rhodomonas sp. & CS-202 & G & 17.5 & & $0.9 \quad(345.9)$ & \\
\hline Rhodomonas sp. & CS-215 & G & 17.5 & $2.42(290.7)$ & $0.67(338.8)$ & \\
\hline \multicolumn{7}{|l|}{ CYANOPHYCEAE } \\
\hline Anabaena cylindrica Lemmermann & $\mathrm{CS}-53$ & MM11 & 17.5 & & $0.67(338.2)$ & \\
\hline Anabaena cylindrica Lemmermann & CS-172 & MM11 & 17.5 & & $0.63(338.5)$ & \\
\hline Oscillatoria sp. & $\mathrm{CS}-52$ & $\mathrm{f}_{2}$ & 17.5 & & $0.6 \quad(339.0)$ & \\
\hline Oscillatoria sp. & CS-180 & $\mathrm{f}_{2}$ & 27 & $0.89(293.7)$ & $0.56(339.7)$ & \\
\hline Synechococcus sp. & CS-94 & $\mathrm{fE}$ & 17.5 & & $0.72(338.1)$ & \\
\hline Synechococcus sp. & CS-197 & $f_{2}$ & 17.5 & & $0.61(339.9)$ & \\
\hline Synechocystis sp. & CS-95 & $\mathrm{fE}$ & 17.5 & $0.50(293.8)$ & $0.81(340.2)$ & \\
\hline \multicolumn{7}{|l|}{ DINOPHYCEAE } \\
\hline $\begin{array}{l}\text { Alexandrium affine (Inoue et Fukuyo) } \\
\text { Balech }\end{array}$ & $\begin{array}{l}\mathrm{CS}-312 \\
(\mathrm{AABB} 01)\end{array}$ & GSe & 15 & & $1.21(333.9)$ & \\
\hline $\begin{array}{l}\text { Alexandrium catenella (Whedon et Kofoid) } \\
\text { Balech }\end{array}$ & $\begin{array}{l}\text { CS-313/1 } \\
\text { (ACPP01) }\end{array}$ & GSe & 15 & & $1.17(336.1)$ & \\
\hline $\begin{array}{l}\text { Alexandrium catenella (Whedon et Kofoid) } \\
\text { Balech }\end{array}$ & $\begin{array}{l}\text { CS-316/1 } \\
\text { (ACJP01) }\end{array}$ & $\mathrm{GSe}$ & 15 & & $1.70(332.6\}$ & \\
\hline $\begin{array}{l}\text { Alexandrium catenella (Whedon et Kofoid) } \\
\text { Balech. }\end{array}$ & $\begin{array}{l}\text { CS-316/1 } \\
(A C C A 01)\end{array}$ & GSe & 15 & & $2.47\{334.4\}$ & \\
\hline Alexandrium margalefi Balech & $\begin{array}{l}\text { CS-322 } \\
\text { (AMADE01) }\end{array}$ & GSe & 15 & & $3.00(337.4)$ & $2.3(364)$ \\
\hline Alexandrium minutum Halim & $\begin{array}{l}\text { CS-323/2 } \\
\text { (AMAD02) }\end{array}$ & GSe & 15 & & $1.42(337.2)$ & \\
\hline Alexandrium minutum Halim & $\begin{array}{l}\text { CS-323/4 } \\
\text { (AMAD04) }\end{array}$ & GSe & 15 & & $1.55(336.7)$ & \\
\hline Alexandrium minutum Halim & $\begin{array}{l}\text { CS-324/13 } \\
\text { (AMAD13) }\end{array}$ & GSe & 15 & & $1.06(337.3)$ & \\
\hline Alexandrium minutum Halim & $\begin{array}{l}\text { CS-324/17 } \\
\text { (AMAD17) }\end{array}$ & GSe & 15 & & $1.81(336.5)$ & \\
\hline Alexandrium tamarense (Lebour) Balech & $\begin{array}{l}\text { CS-298 } \\
\text { (ATBB01) }\end{array}$ & GSe & 15 & & $1.18(337)$ & \\
\hline Alexandrium tamarense (Lebour) Balech & $\begin{array}{l}\text { CS-299 } \\
\text { (ATJP01) }\end{array}$ & GSe & 15 & & $1.19(336.9)$ & \\
\hline Amphidinium carterae Hulburt & $\mathrm{CS}-21$ & $\mathrm{G}$ & 17.5 & $0.18(280.6)$ & $0.79(337.5)$ & \\
\hline
\end{tabular}


Table 1 (continued)

\begin{tabular}{|c|c|c|c|c|c|c|}
\hline \multirow[t]{2}{*}{ Class and species } & \multirow{2}{*}{$\begin{array}{l}\text { CSIRO } \\
\text { culture code }\end{array}$} & \multirow{2}{*}{$\begin{array}{l}\text { Culture } \\
\text { medium }^{\text {a }}\end{array}$} & \multirow{2}{*}{$\begin{array}{l}\text { Growth } \\
\text { temp. }\left({ }^{\circ} \mathrm{C}\right)\end{array}$} & \multicolumn{3}{|c|}{ Abs. ratio of major UV peaks:chl a $(665 \mathrm{~nm})$} \\
\hline & & & & $280-320 \mathrm{~nm}$ & $320-340 \mathrm{~nm}$ & $340-390 \mathrm{~nm}$ \\
\hline Amphidinium carterae Hulburt & CS-212 & G & 17.5 & $0.59(280.6)$ & $0.88(337.8)$ & \\
\hline Amphidinium klebsii Kofoid et Swezy & $\mathrm{CS}-33$ & G & 17.5 & & $0.93(338.3)$ & \\
\hline Amphidinium sp. & CS -109 & $\mathrm{G}_{2}$ & 25 & & $0.93(337.7)$ & \\
\hline Amphidinium sp. & CS-259 & $\mathrm{G}_{2}$ & 25 & & $1.24(338)$ & \\
\hline Gymnodinium catondtum Graham & $\begin{array}{l}\text { CS-301/2 } \\
\text { (GCDE02) }\end{array}$ & GSe & 1.7 .5 & & $2.17(336.3)$ & \\
\hline Gymnodinium catenatum Graham & $\begin{array}{l}\text { CS-301/8 } \\
\text { (GCDE08) }\end{array}$ & GSe & 17.5 & & $2.07(336.7)$ & $1.69(380.5)$ \\
\hline Gymnodinium catenatum Graham & $\begin{array}{l}\text { CS-302/20 } \\
\text { (GCHU20) }\end{array}$ & GSe & 17.5 & & $1.84(337.4)$ & $1.62(385.4)$ \\
\hline Gymnodinium catenatum Graham & $\begin{array}{l}\text { CS-302/22 } \\
\text { (GCHU22) }\end{array}$ & GSe & 17.5 & & $1.83(335.7)$ & $1.63(384.3)$ \\
\hline Gymnodinium catenatum Graham & $\begin{array}{l}\text { CS }-302 / 9 \\
\text { (GCHUO9) }\end{array}$ & GSe & 17.5 & & $2.48(339.4)$ & $2.57(374.7)$ \\
\hline Gymnodinium catenatum Graham & $\begin{array}{l}\mathrm{CS}-304 / 2 \\
\text { (GCHA02) }\end{array}$ & GSe & 1.7 .5 & & $1.49(337.6)$ & $1.56(390)$ \\
\hline Gymnodinium catenatum Graham & $\begin{array}{l}\text { CS-305 } \\
\text { (GCJP10) }\end{array}$ & GSe & 17.5 & & $3.5(337.1)$ & $1.5 \quad(377.4)$ \\
\hline Gymnodinium catenatum Graham & $\begin{array}{l}\text { CS-306/4 } \\
\text { (GCSP04) }\end{array}$ & GSe & 17.5 & & $2.94(338.8)$ & $2.6 \quad(373.9)$ \\
\hline Gymnodinium catenatum Graham & $\begin{array}{l}\text { CS-309/1 } \\
\text { (GCPT01) }\end{array}$ & GSe & 17.5 & $4.0 \quad(319.7)$ & & $\begin{array}{l}4.68(345) \\
6.75(370.3)\end{array}$ \\
\hline Gymnodinium catenatum Graham & $\begin{array}{l}\text { CS-309/3 } \\
\text { (GCPT03) }\end{array}$ & GSe & 17.5 & & $2.65(340)$ & $3.46(372.3)$ \\
\hline Gymnodinium galatheanum (Braarud) Taylor & $\mathrm{CS}-214$ & GSe & 17.5 & & $0.96(337.5)$ & \\
\hline Gymnodinium sanguineum Hirasaki & CS-35 & G & 17.5 & $0.22(281.8)$ & $1.24(335.8)$ & \\
\hline Heterocapsa niei (Loeblich) Morrill et Loeblich & CS-36 & $\mathrm{G}$ & 17.5 & & $1.33(333.7)$ & \\
\hline Heterocapsa niei (Loeblich) Morrill et Loeblich & CS-89 & $\mathrm{G}$ & 17.5 & & $1.65(323.8)$ & \\
\hline Katodinium of. rotundatum (Lohmann) Loeblich & CS-290/2 & GSe & 15 & & $1.14(332.1)$ & \\
\hline Kryptoperidinium foliaceum (Stein) Lindemann & CS-37 & G & 17.5 & & $0.70(337.9)$ & \\
\hline Peridinium balticum (Lev.) Lemm & CS-38 & $G$ & 17.5 & $0.67(295.9)$ & $0.59(338.2)$ & \\
\hline Prorocentrum compressum (Bailey) Abé ex Dodge & Proro 1 & GSe & 17.5 & & $1.32(336.2)$ & \\
\hline Prorocentrum gracile Shutt & CS-80 & G & 17.5 & & $1.33(337.3)$ & \\
\hline Prorocentrum micans Ehrenberg & CS -27 & $\mathrm{G}$ & 17.5 & & $0.97(336)$ & \\
\hline Scrippsiella sp. & CS-168 & G & 17.5 & & $0.99(336.3)$ & \\
\hline Scrippsiella sp. & CS-295/1 & GSe & 17.5 & & $1.79(336.8)$ & \\
\hline Scrippsiella sp. & $\operatorname{CS}-297$ & GSe & 17.5 & & $1.10(336.8)$ & \\
\hline Symbiodinium microadriaticum Freud. & $\mathrm{CS}-73$ & G & 27 & & $0.88(337.5)$ & \\
\hline Symbiodinium microadriaticum Freud. & CS-153 & $\mathrm{f}_{2}$ & 27 & & $0.88(336.9)$ & \\
\hline Symbiodinium microadriaticum Freud. & CS-154 & $\mathrm{f}_{2}$ & 27 & & $1.17(336.9)$ & \\
\hline Symbiodinium microadriaticum Freud. & CS-156 & $\mathrm{f}_{2}$ & 27 & & $0.93(337.3)$ & \\
\hline Symbiodinium microadriaticum Freud. & CS- 158 & $\mathrm{f}_{2}$ & 27 & & $0.93(336.6)$ & \\
\hline Symbiodinium microadriaticum Freud. & CS-164 & $\mathrm{f}_{2}$ & 27 & & $0.90(337.3)$ & \\
\hline Woloszynskia sp. & $\begin{array}{l}\text { CS-341 } \\
\text { (Wol 1) }\end{array}$ & GSe & 27 & & $3.40(339.7)$ & \\
\hline Woloszynskia sp. (Shearwater ballast) & & GSe & 27 & & $1.56(335)$ & \\
\hline $\begin{array}{l}\text { EUGLENOPHYCEAE } \\
\text { Euglena gracilis Klebs }\end{array}$ & CS-66 & $\mathrm{MBL} / \mathrm{NB}_{2}$ & 17.5 & & $0.58(339.1)$ & \\
\hline EUSTIGMATOPHYCEAE & & & & & & \\
\hline Eustigmatos vischeri Hibberd & CS -144 & BB & 17.5 & & $0.53(336.7)$ & \\
\hline Nannochloropsis oculata (Droop) Green & CS-179 & $\mathrm{f}_{2}$ & 17.5 & & $0.47(338.1)$ & \\
\hline Nannochloropsis oculata (Droop) Green & CS-189 & $\mathrm{fE}_{2}$ & 17.5 & & $0.52(337.5)$ & \\
\hline Nannochloropsis oculata (Droop) Green & CS-216 & $\mathrm{fE}_{2}$ & 17.5 & & $0.69(340.5)$ & \\
\hline Nannochloropsis salina Hibberd & CS. 190 & $\mathrm{f}_{2}$ & 17.5 & & $0.52(337.8)$ & \\
\hline Nannochloropsis salina Hibberd & CS-191 & $\mathrm{fE}_{2}$ & 17.5 & & $0.51(337.8)$ & \\
\hline Nannochloropsis sp. & CS-192 & $\mathrm{fE}_{2}$ & 17.5 & & $0.48(337.5)$ & \\
\hline Nannochloropsis-like & CS-246 & $\mathrm{f}_{2}$ & 27 & & $0.64(337.7)$ & \\
\hline Vischeria helvetica (Vischer et Pasher) Hibberd & $\mathrm{CS}-143$ & $\mathrm{BB}$ & 17.5 & & $0.59(338.1)$ & \\
\hline Vischeria punctata Vischer & CS-142 & $\mathrm{BB}$ & 17.5 & & $0.72(330)$ & \\
\hline PRASINOPHYCEAE & & & & & & \\
\hline $\begin{array}{l}\text { Mantoniella squamata (Manton et Parke) } \\
\text { Desikachary }\end{array}$ & CS-199 & $\mathrm{f}_{2}$ & 17.5 & & $0.91(339)$ & \\
\hline Micromonas pusilla (Butcher) Manton et Parke & CS-86 & $\mathrm{G}$ & 17.5 & & $0.97(338.9)$ & \\
\hline Micromonas pusilla (Butcher) Manton et Parke & $\mathrm{CS}-170$ & G & 27 & & $0.99(339.5)$ & \\
\hline Micromonas pusilla (Butcher) Manton et Parke & CS- 222 & $\mathrm{fE}_{2}$ & 17.5 & $0.81(295.7)$ & $0.81(339.3)$ & \\
\hline
\end{tabular}


Table 1 (continued)

\begin{tabular}{|c|c|c|c|c|c|}
\hline \multirow{2}{*}{ Class and species } & \multirow{2}{*}{$\begin{array}{l}\text { CSIRO } \\
\text { culture code }\end{array}$} & \multirow{2}{*}{$\begin{array}{l}\text { Culture } \\
\text { medium }\end{array}$} & \multirow{2}{*}{$\begin{array}{l}\text { Growth } \\
\text { temp }\left({ }^{\circ} \mathrm{C}\right)\end{array}$} & \multicolumn{2}{|c|}{ Abs. ratio of major UV peaks:chl a $(665 \mathrm{~nm})$} \\
\hline & & & & $280-320 \mathrm{~nm}$ & $320-340 \mathrm{~nm} \quad 340-390 \mathrm{~nm}$ \\
\hline Nephroselmis minuta (Carter) Butch. & C5-207 & $\mathrm{G}$ & 17.5 & & $0.72(339.4)$ \\
\hline Nephroselmis rotunda (Carter) Fott & CS -223 & $\mathrm{fE}_{2}$ & 17.5 & $0.70(294.7)$ & $0.91(340)$ \\
\hline Pseudoscourfieldia marina (Throndsen) Manton & CS-208 & $\mathrm{G}$ & 17.5 & & $0.97(338.3)$ \\
\hline Pycnococcus provasolii Guillard & CS-185 & $\mathrm{f}_{2}$ & 17.5 & & $0.96(339.4)$ \\
\hline Pyramimonas cordata McFadden & CS-140 & $\mathrm{G}_{2}$ & 17.5 & & $0.97(334.8)$ \\
\hline $\begin{array}{l}\text { Pyramimonas gelidicola McFadden, } \\
\text { Moestrup et Wetherbee }\end{array}$ & CS-139 & $f_{2}$ & 5 & & $0.74(339.2)$ \\
\hline Pyramimonas oltmansii Schiller & CS-225 & $\mathrm{fE}_{2}$ & 17.5 & & $0.88(339.9)$ \\
\hline Pyramimonas propulsa Moestrup et Hill & CS-226 & $\mathrm{fE}_{2}$ & 17.5 & & $0.76(338.5)$ \\
\hline Tetraselmis chuii Butcher & CS-26 & $\mathrm{f}_{2}$ & 17.5 & & $0.67(339.3)$ \\
\hline Tetraselmis suecica (Kylin) Butcher & CS-56 & $\mathrm{f}_{2}$ & 17.5 & & $0.72(339.3)$ \\
\hline Tetraselmis suecica (Kylin) Butcher & CS-187 & $\mathfrak{f}_{2}$ & 17.5 & $0.47(290)$ & $0.63(339.1)$ \\
\hline Tetraselmis $\mathrm{sp}$ & CS-91 & $\mathrm{f}_{2}$ & 17.5 & & $0.68(340.6)$ \\
\hline Unidentified prasinophyte (CCMP-BT5) & CS-211 & $\mathrm{f}_{2}$ & 17.5 & & $1.2 \quad(339.3)$ \\
\hline \multicolumn{6}{|l|}{ PRYMNESIOPHYCEAE } \\
\hline Chrysachromulina camella Leadbeater et Manton & CS-268 & GSe & 15 & & $1.27(337)$ \\
\hline Chrysochromulina hirta Manton & CS-228 & GSe & 15 & & $1.31(337.1)$ \\
\hline Chrysochromulina kappa Parke et Manton & CS-269 & GSe & 15 & & $1.20(337)$ \\
\hline Chrysochromulina minor Parke et Manton & CS-270 & GSe & 15 & & $1.38(337)$ \\
\hline Chrysochromulina strobilus Parke el Manton & CS-271 & GSe & 15 & & $1.65(337)$ \\
\hline Chrysochromnulina strobilus Parke et Manton & CS-231 & GSe & 15 & & $1.49(337.3)$ \\
\hline Chrysochromulinasp. & CS-219 & $\mathrm{fE}_{2}$ & 15 & & $1.37(337.2)$ \\
\hline Chrysotila lamellosa Anand & CS -272 & GSe & 15 & & $0.88(337)$ \\
\hline $\begin{array}{l}\text { Cricosphaera carterae (Braarud et Fagerland) } \\
\text { Braarud }\end{array}$ & CS-40 & $D$ & 17.5 & & $0.85(339)$ \\
\hline Crystallolithus hyalınus Gaarder et Markali & CS-273 & GSe & 15 & & $1.05(337)$ \\
\hline Diacronema v/kianum Prauser & CS-266 & GSe & 15 & & $0.67(337)$ \\
\hline Dicrateria inornata Parke & CS-267 & GSe & 15 & & $1.23(337)$ \\
\hline Emiliania huxleyi (Lohmanji) Hay et Mohler & CS-57 & $\mathrm{f}_{2}$ & 17.5 & & $1.49(337.7)$ \\
\hline Emiliania huxleyi (Lohmann) Hay et Mohler & $\mathrm{CS}-274$ & GSe & 15 & & $1.24(337)$ \\
\hline Emiliania huxleyi (Lohmann) Hay et Mohler & $\mathrm{CS}-275 / 2$ & GSe, $\mathrm{K}$ & 15 & & $1.38(337)$ \\
\hline Imantonia rotunda Reynolds & CS-194 & $\mathrm{fE}_{2}$ & 17.5 & & $1.34(337.1)$ \\
\hline Isochrysis galbana Parke & CS-22 & $\mathrm{f}_{2}$ & 17.5 & & $0.76(338)$ \\
\hline Isochrysis sp. & CS-177 & $\mathrm{I}_{2}$ & 17.5 & $1.04(279.1)$ & $0.84(337.8)$ \\
\hline Ochrosphaera neopolitana Schussing & CS-285 & GSe & 15 & & $1.05(337)$ \\
\hline Pavlova gyrans Butcher & CS-213 & $\mathrm{f}_{2}$ & 17.5 & & $0.73(337.9)$ \\
\hline Pavlova lutheri (Droop) Green & CS-23 & $\mathrm{f}_{2}$ & 17.5 & & $0.81\{338.9\}$ \\
\hline Pavlova lutheri (Droop) Green & CS-182 & $\mathrm{f}_{2}$ & 17.5 & & $0.57\{338.9\}$ \\
\hline Pavlova pinguis Green & CS-286 & GSe & 15 & & $0.76(337)$ \\
\hline Pavlova salina Carter (Green) & CS -49 & $\mathrm{f}_{2}$ & 17.5 & & $0.72(337.5)$ \\
\hline Pavlovasp. & CS-63 & $\mathrm{f}_{2}$ & 17.5 & & $0.79(337.3)$ \\
\hline Pavlova sp. & CS-50 & $\mathrm{f}_{2}$ & 17.5 & & $0.70(337.6)$ \\
\hline Phaeocystis pouchetii (Hariot) Lagerheim & CS-239 & GSe & 15 & & $1.14(336.9)$ \\
\hline Phaeocystis pouchetii (Hariot) Lagerheim & CS -240 & $\mathrm{GSe}$ & 15 & & $1.15(337.8)$ \\
\hline Phaeocystis pouchetii (Hariot) Lagerheim & CS-241 & $\mathrm{GSe}$ & 15 & & $1.34(337.2)$ \\
\hline Phaeocystis pouchetii (Hariot) Lagerheim & $\operatorname{CS}-243$ & $\mathrm{G}_{5}$ & 5 & & $1.36(336.3)$ \\
\hline Phaeocystis pouchetii (Hariot) Lagerheim & CS-244 & $\mathrm{G}_{5}$ & 5 & $2.89(3157)$ & $2.32(337)$ \\
\hline Prymnesium parvum Carter & CS-288 & GSe & 15 & & $0.87(337)$ \\
\hline $\begin{array}{l}\text { Pleurochrysis aff. carterae (Braarud et } \\
\text { Fagerland) Christiansen }\end{array}$ & CS-287 & GSe & 15 & & $0.68(337)$ \\
\hline Prymnesiophyte 120 & CS -120 & $\mathrm{f}_{2}$ & 27 & $1.46(296)$ & $0.96(335.9)$ \\
\hline Pseudoisochrysis paradoxa Ott & CS-186 & $\mathrm{f}_{2}$ & 17.5 & $0.75(279)$ & $0.71(338.3)$ \\
\hline \multicolumn{6}{|l|}{ RAPHIDOPHYCEAE } \\
\hline Chattonella antiqua (Hada) Ono & CS-171 & G & 17.5 & & $1.43(333.3)$ \\
\hline Fibrocapsa sp. & CS -220 & $\mathrm{fE}_{2}$ & 17.5 & & $1.86(325)$ \\
\hline Heterosigma carterae (Hulbert) Taylor & CS-39 & $\mathrm{D}$ & 17.5 & & $0.69(337)$ \\
\hline Heterosigma carterae (Hulbert) Taylor & CS-169 & $\mathrm{G}$ & 17.5 & & $0.66(337)$ \\
\hline \multicolumn{6}{|l|}{ RHODOPHYCEAE } \\
\hline Porphyndium purpureum (Bory) Drew et Ross & CS-25 & $\mathrm{f}_{2}$ & 17.5 & & $0.54(335)$ \\
\hline
\end{tabular}


A Diatom

Asterionella glacialis CS-135

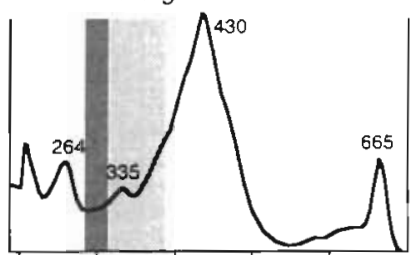

B Raphidophyte

Fibrocapsa sp. CS-220

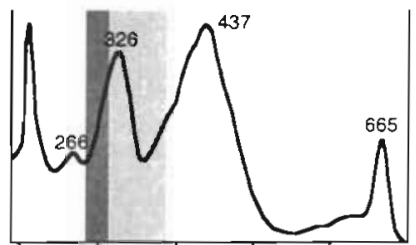

C Cryptomonad

Rhodomonas sp. CS-215

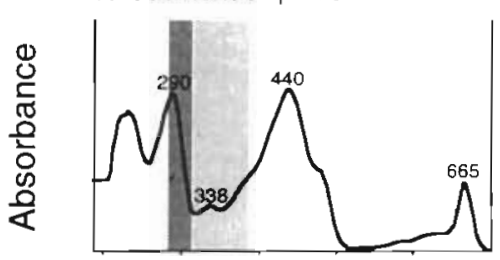

D Cyanophyte

Synechococcus sp. CS-197

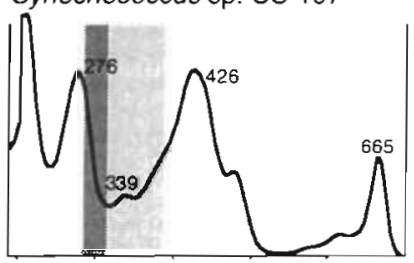

E Prasinophyte

Tetraselmis chuii CS-26

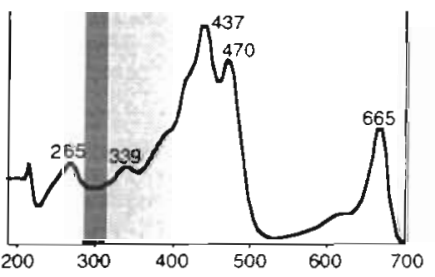

F Prymnesiophyte

Antarctic Phaeocystis pouchetii CS-244

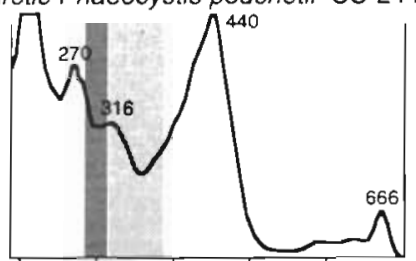

G Dinoflagellate Alexandrium margalefi AMADE01

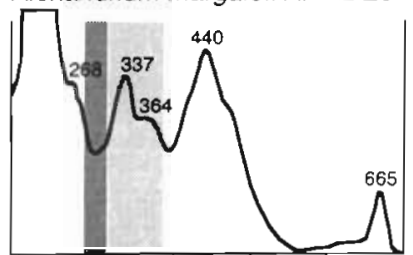

H Dinoflagellate

Gymnodinium catenatum GCJP10

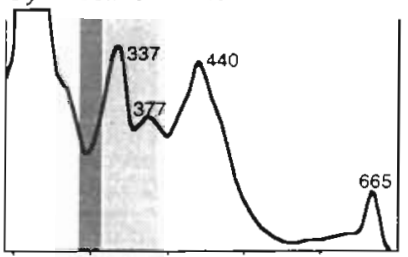

I Dinoflagellate

Gymnodinium catenatum GCPT03

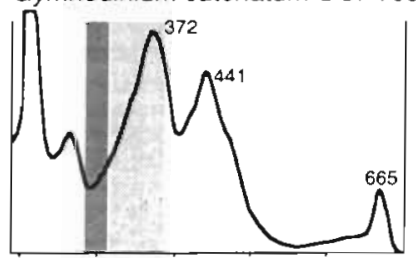

$J$ Dinoflagellate

Gymnodinium catenatum GCPT01

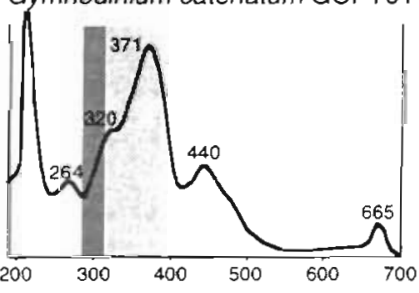

Wavelength $(\mathrm{nm})$

UV-B 280-320 nm

UV-A $320-380 \mathrm{~nm}$

Fig. 1. UV-visible absorption spectra of tetrahydrofuran:methanol (20:80, $\mathrm{v} / \mathrm{v}$ ) extracts of selected microalgae. (A) Asterionella glacialis, CS-135 (diatom); (B) Fibrocapsa sp., CS-220 (raphidophyte); (C) Rhodomonas sp., CS-215 (cryptomonad); (D) Synechococcus sp., CS-197 (cyanophyte); (E) Tetraselmis chuii, CS-26 (prasinophyte); (F) Phaeocystis pouchetii, CS-244 (prymnesiophyte); (G) Alexandrium margalefi, AMADE01 (dinoflagellate); (H) Gymnodinium catenatum, GCJP10 (dinoflagellate): (1) G. catenatum, GCPT03 (dinoflagellate); (J) G. catenatum, GCPT01 (dinoflagellate)

et al. 1994, Carroll \& Shick 1996, Helbling et al. 1996). Lyophilized algal extracts were reconstituted in $80 \%$ aqueous methanol (1/5 volume for Chaetoceros affinis and Heterosigma carterae, equi-volume for Fibrocapsa sp., Woloszynskia sp. and Gymnodinium catenatum). Individual MAAs were separated and quantified by isocratic HPLC on a reverse-phase, Brownlee RP-8 column (Spheri-5, 4.6 i.d. $\times$ $250 \mathrm{~mm}$ ) protected with a RP-8 guard column (Spheri-5, 4.6 i.d. $\times 30 \mathrm{~mm}$ ) with a mobile phase consisting of aqueous $25 \%$ methanol containing $0.1 \%$ acetic acid which was delivered at a flow rate of $0.8 \mathrm{ml}$ $\min ^{-1}$. MAAs were identified by comparison and co-chromatography (where applicable) with authenticated standards and quantified by dual wavelength absorbance at 313 and $340 \mathrm{~nm}$ (Waters Model 440 dual wavelength detector) and peak area integration (Spectra-Physics 4400 dual channel integrator). Chromatographic standards were previously prepared (W. Dunlap) from the macroalgae Porphyra tenera (porphyra-334: Dunlap \& Yamamoto 1995) and Mastocarpus stellatus (shinorine: Carroll \& Shick 1996), the zoanthid Palythoa tuberculosa (mycosporine-glycine, palythine and palythinol: Dunlap \& Chalker 1986j, the ascidian Lissoclinum patella (mycosporine-glycine and shinorine: Dunlap \& Yamamoto 1995), the sea anemone Anthopleura elegantissima (mycosporinetaurine, shinorine, porphyra-334 and mycosporine-2glycine: Stochaj et al. 1994) and the ocular lens of the coral trout Plectropomus leopardus (palythine, asterina-330, palythinol and palythene: Dunlap et al. 1989).

\section{RESULTS}

The relative proportions of UVA- and UVB-absorbing compounds (280 to $390 \mathrm{~nm}$ ) compared to chl a (665 nm) in extracts of microalgae from 12 classes are shown in Table 1, together with the culture conditions for each of the 152 species $t=206$ strains). A total of 85 genera were represented, with 26 strains from tropical waters, 173 from subtropical and temperate waters and 7 from Antarctic waters. These included surface-living, bloom-forming strains 


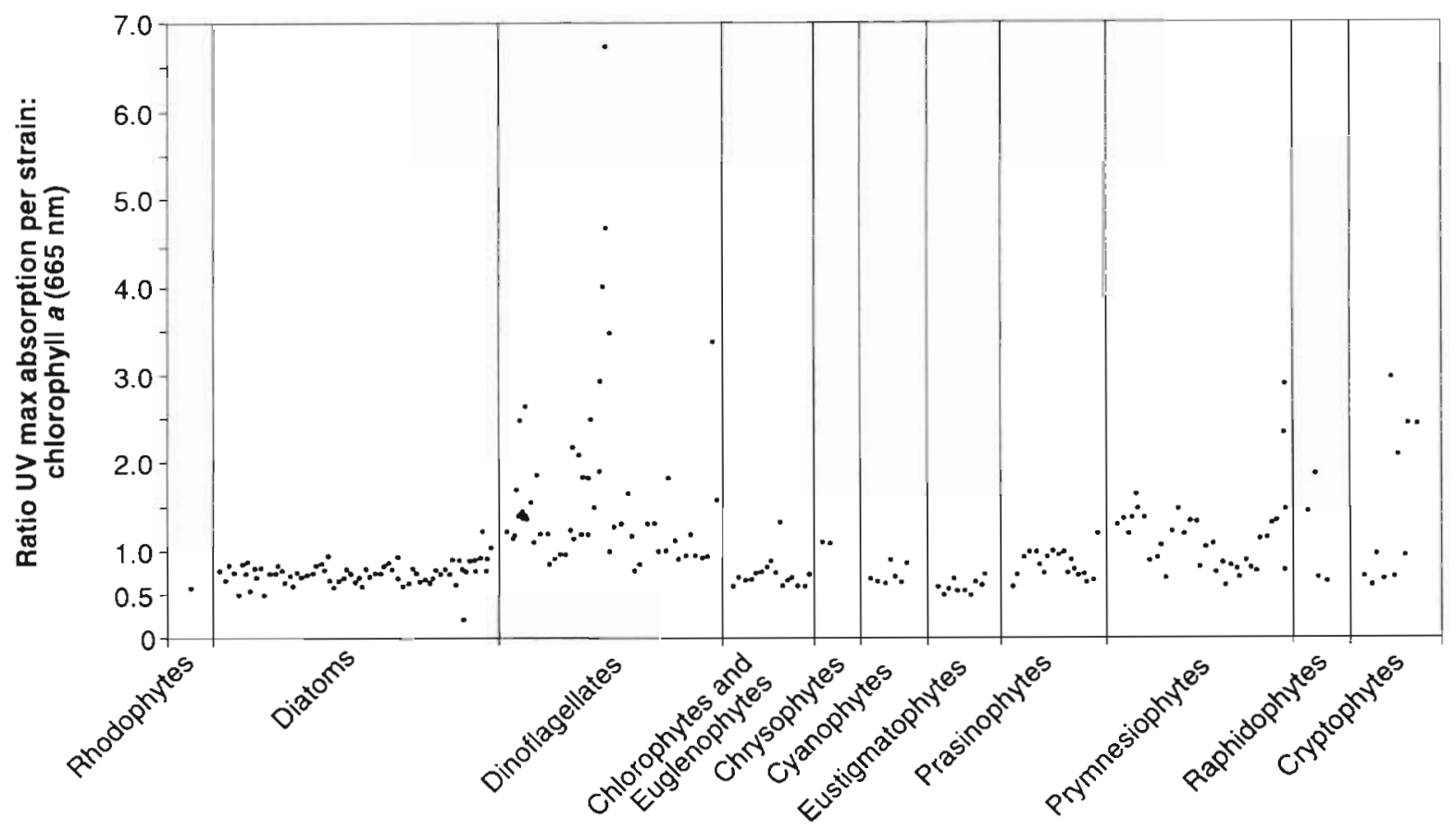

Fig. 2. Scatter plot of ratios of the maximum UV absorbance (290 to $390 \mathrm{~nm}$ ) to chl a absorbance (665 nm) for each algal strain examined in Table 1. Data are grouped according to algal class

(dinoflagellates, prymnesiophytes, cryptomonads and raphidophytes), many species from coastal waters and some from the deep euphotic zone (e.g. picoplanktonic cyanobacteria).

Extracts of microalgae showed environmentally relevant, ultraviolet absorption maxima in 3 main regions: UVB (280 to $320 \mathrm{~nm})$, UVA (320 to $340 \mathrm{~nm})$ and nearUVA $(340$ to $390 \mathrm{~nm})$. All strains, without exception, had maxima in the UVA region between 320 and $340 \mathrm{~nm}$ (most were close to $337 \mathrm{~nm}$ ), 22 strains showed strong absorption in the UVB region (280 to $320 \mathrm{~nm}$ ), and 9 strains of the dinoflagellate Gymnodinium catenatum had high absorbance in the near-UVA (340 to $390 \mathrm{~nm}$ ) (Table 1).

UV-visible spectra of tetrahydrofuran-methanol extracts of 10 selected strains are shown in Fig. 1. The diatom Asterionella glacialis (Fig. 1A) and the prasinophyte Tetraselmis chuii (Fig. 1E) were 2 examples of species with very low absorbance in UVA and UVB regions. In contrast, the raphidophyte Fibrocapsa sp. (Fig. 1B), the prymnesiophyte Phaeocystis pouchetii (Fig. $1 \mathrm{~F}$ ), and the dinoflagellates Alexandrium margalefi (Fig. 1G) and Gymnodinium catenatum (Fig. 1H, I, J) were rich in UVA- and UVB-absorbing compounds, with some species showing multiple peaks in the UVA and UVB regions.

Fig. 2 presents a scatter plot of the ratio of the maximum UV absorbance to that of chl a at $665 \mathrm{~nm}$ for each strain listed in Table 1, grouping the data according to algal class. Strains rich in UV-absorbing compounds (ratios 1 to 6.75) came mostly from the bloom-forming flagellate classes: dinoflagellates, prymnesiophytes, raphidophytes and cryptomonads. The lowest ratios $(<0.90)$ were found in the diatoms, eustigmatophytes, chlorophytes, prasinophytes, cyanophytes, chrysophytes, euglenophytes and rhodophytes.

A summary of all UV to chl a ratios by algal class is shown in Table 2. The majority of microalgae had UV:chl a ratios less than 1 (range 0.5 to 0.9 , see Fig. 2). A second group had slightly higher ratios (0.9 to 1.4$)$. It included the chrysophytes, and some of the prasinophytes and prymnesiophytes. A third group had the highest ratios (1.4 to 6.75 ). It included many bloomforming members of the cryptomonads, dinoflagellates, prymnesiophytes and raphidophytes. Exceptions to these generalisations for each class were found, but the main trends were as specified (see Fig. 2). These data show that algal extracts differ across classes and strains of the same species (Table 3), having a range of UV-absorbing peaks with different patterns of absorption maxima and intensities, in both UVA and UVB regions.

The dinoflagellates were a special group, showing the greatest variations in UV-absorbing compounds across species and across strains of the same species (Tables $1 \& 3$, Figs. $1 \& 2$ ). Some dinoflagellates had very low UV:chl a ratios (e.g. Amphidinium carterae). The 2 endosymbiont-containing species-Peridinium balticum and Kryptoperidinium foliaceum-also had low ratios, possibly reflecting the presence of their 
Table 2. Summary of the number of strains studied from 12 algal classes with their range of ratios of maximum UV absorbance (280 to $390 \mathrm{~nm}$ ) to chlorophyll a absorbance $(665 \mathrm{~nm})$

\begin{tabular}{|lrc|}
\hline Algal class & $\begin{array}{c}\text { No. of } \\
\text { strains }\end{array}$ & $\begin{array}{c}\text { Range of absorbance ratios } \\
\text { of max. UV abs }(280-390 \mathrm{~nm}) \\
\text { to chl a }(665 \mathrm{~nm})\end{array}$ \\
\hline Bacillariophyceae & 57 & $0.18-1.22$ \\
Chlorophyceae & 15 & $0.34-1.35$ \\
Chrysophyceae & 2 & $1.06-1.08$ \\
Cryptophyceae & 10 & $0.47-2.96$ \\
Cyanophyceae & 7 & $0.50-0.89$ \\
Dinophyceae & 47 & $0.18-6.75$ \\
Euglenophyceae & 1 & 0.58 \\
Eustigmatophyceae & 10 & $0.47-0.72$ \\
Prasinophyceae & 17 & $0.47-1.20$ \\
Prymnesiophyceae & 35 & $0.57-2.89$ \\
Raphidophyceae & 4 & $0.66-1.86$ \\
Rhodophyceae & 1 & 0.54 \\
Total & 206 & $0.18-6.75$ \\
\hline
\end{tabular}

chrysophyte or diatom endosymbionts (Tomas \& Cox 1973, Jeffrey et al. 1975, Jeffrey \& Vesk 1976). Other dinoflagellates, such as the surface bloom-forming species Gymnodinium catenatum, were rich in UVabsorbing compounds, with ratios of up to 4.0 at $319.7 \mathrm{~nm}, 4.6$ at $345 \mathrm{~nm}$ and 6.75 at $370 \mathrm{~nm}$ (CS-309/1, GCPT01). Table 3 shows that strains of the same species either had very similar UV:chl a ratios (e.g. Amphidinium carterae, Symbiodinium microadriaticum and Heterocapsa niel) or varied widely (e.g. Alexandrium catenella, Alexandrium minutum and Gymnodinium catenatum). These data indicate that even in species rich in UV-absorbing compounds, significant strain variations are found.

The UV-absorbing properties of natural phytoplankton field populations obtained by net tows from the CSIRO wharf station (Derwent River Estuary) are shown in Fig. 3. When dinoflagellates were the main component of the phytoplankton (Fig. 3A, B), high values were obtained for UV:chl a absorbance ratios (e.g. 2.4 at $337 \mathrm{~nm}$ and 3.1 at $339 \mathrm{~nm}$ for the 2 samples, respectively). When diatoms were the main component (Fig. 3C, D), lower ratios (1.4 at $335 \mathrm{~nm}$ and 1.5 at $336 \mathrm{~nm}$ ) were seen. The UV-visible spectrum of a field sample in which Gymnodinium catenatum was dominant (Fig. 3A) closely resembled that of one maintained culture of Gymnodinium catenatum (Fig. 1H), originally isolated from a local estuary.

Five microalgal cultures were examined by isocratic HPLC to check for the presence of MAAs. The strains were selected on the basis of their UV:chl a absorbance ratios obtained by spectrophotometry to represent a range of UV-absorbing properties (Fig. 4). The diatom
Chaetoceros affinis had a low ratio ( $\mathrm{UV}_{33 \pi \mathrm{mm}}: \mathrm{chl} \mathrm{a}=$ 0.75), the raphidophyte Heterosigma carterae ratio was also low (UV $338 \mathrm{~nm}$ : chl $a=0.66)$, the raphidophyte Fibrocapsa sp. had a high ratio $\left(\mathrm{UV}_{323 \mathrm{~nm}}\right.$ : chl $a=2.33$ ), the ratio of the dinoflagellate Gymnodinium catenatum was also high $\left(\mathrm{UV}_{370 \mathrm{~nm}}\right.$ : chl $\left.a=6.56\right)$ and that of the dinoflagellate Woloszynskia sp. was moderately low $\left(\mathrm{UV}_{365 \mathrm{~nm}}\right.$ : chl $\left.\mathrm{a}=1.13\right)$.

HPLC analyses of the 5 species are shown in Fig. 5. Chaetoceros affinis with a low UV:chl a ratio (0.75) gave no trace of MAAs, but the other 4 species had various combinations of MAA components. Heterosigma carterae, with a low UV:chl a ratio (0.66) contained both shinorine and asterina-330. The raphidophyte Fibrocapsa sp. with a high UV:chl a ratio (2.33) showed 2 major fractions, mycosporine-glycine and porphyra-334, as well as 3 minor components (palythine, asterina-330 and 1 unknown). The dinoflagellate Woloszynskia sp., with a UV:chl a ratio of 1.13 , had 2 major components, shinorine and porphyra-334, and 5 minor fractions, mycosporine-glycine, palythine and 3 unknowns. The dinoflagellate Gymnodinium catenatum had the highest UV:chl a absorbance ratio (6.56), but only 3 MAA fractions could be identified in reason-

Table 3. Variation in the ratios of UV absorption maxima in the $320-340 \mathrm{~nm}$ region to chlorophyll a absorbance (665 $\mathrm{nm}$ ) in extracts from selected dinoflagellate species and strains

\begin{tabular}{|c|c|c|}
\hline Dinoflagellate species & $\begin{array}{l}\text { No. of } \\
\text { strains }\end{array}$ & $\begin{array}{c}\text { Range of abs, ratios } \\
\text { UV }(320-340 \mathrm{~nm}) \\
\text { chl a }(665 \mathrm{~nm})\end{array}$ \\
\hline Alexandrium affine & 1 & 1.21 \\
\hline Alexandrium catenella & 3 & $1.17-2.47$ \\
\hline Alexandrium margelefi & 1 & 2.66 \\
\hline Alexandrium minutum & 4 & $1.06-1.81$ \\
\hline Alexandrium tamarense & 2 & $1.18-1.19$ \\
\hline Amphidinium carterae & 2 & $0.79-0.88$ \\
\hline Amphidinium klebsii & 1 & 0.93 \\
\hline Amphidinium sp. & 2 & $0.93-1.24$ \\
\hline Gymnodinium catenatum ${ }^{d}$ & 10 & $1.49-4.68$ \\
\hline Gymnodinium galatheanum & 1 & 0.96 \\
\hline Gymnodinium sanguineum & 1 & 1.24 \\
\hline Heterocapsa niei & 2 & $1.33-1.65$ \\
\hline Katodinium cf. rotundatum & 1 & 1.14 \\
\hline Kryptoperidinium foliaceum ${ }^{b}$ & 1 & 0.70 \\
\hline Peridinium balticum ${ }^{b}$ & 1 & 0.59 \\
\hline Prorocentrum compressum & 1 & 1.32 \\
\hline Prorocentrum gracile & 1 & 1.33 \\
\hline Prorocentrum micans & 1 & 0.97 \\
\hline Scrippsiella sp. & 3 & $0.99-1.79$ \\
\hline Symbiodinum microadriaticum & 6 & $0.88-1.17$ \\
\hline Woloszynskia sp. & 2 & $1.56-3.40$ \\
\hline \multicolumn{3}{|c|}{$\begin{array}{l}\text { Note ratio of UV:chI a absorbance in the range } 340 \text { to } 390 \\
\text { nm was } 6.75(370.3 \mathrm{~nm}) \text { for strain GCPT01 (see Table 1) } \\
{ }^{\mathrm{b} C o n t a i n} \text { chrysophyte-like endosymbionts with. fucoxan- } \\
\text { thin containing chloroplasts (Tomas \& Cox } 1973 \text {, Jeffrey } \\
\text { et al. } 1975 \text {, Jeffrey \& Vesk } 1976 \text { ) }\end{array}$} \\
\hline
\end{tabular}




\section{Wavelength $(\mathrm{nm})$}

UV-B $280-320 \mathrm{~nm}$
UV-A $320-380 \mathrm{~nm}$
Fig. 3. UV-visible absorption spectra of tetrahydrofuran:methanol $(2080, \mathrm{v} / \mathrm{v})$ extracts of natural phytoplankton from the Derwent River Estuary, Hobart, Tasmania (CSIRO wharf station). Major species present, 337:665 nm ratios and sample collection date are given: (A) Gymnodinium catenatum bloom (dinoflagellates), ratio 2.4, 16 May 1991; (B) Dinophysis spp. and Ceratium spp. (dinoflagellates), ratio 3.1, 22 July 1992; (C) Chaetoceros spp. and Nitzschia spp. (diatoms), ratio 1.4, $11 \mathrm{March}$ 1991; (D) Coscinodiscus sp. (diatoms) with some Dinophysis spp. (dinoflagellates), ratio $1.5,15$ September 1992

\section{A Gymnodinium catenatum bloom}
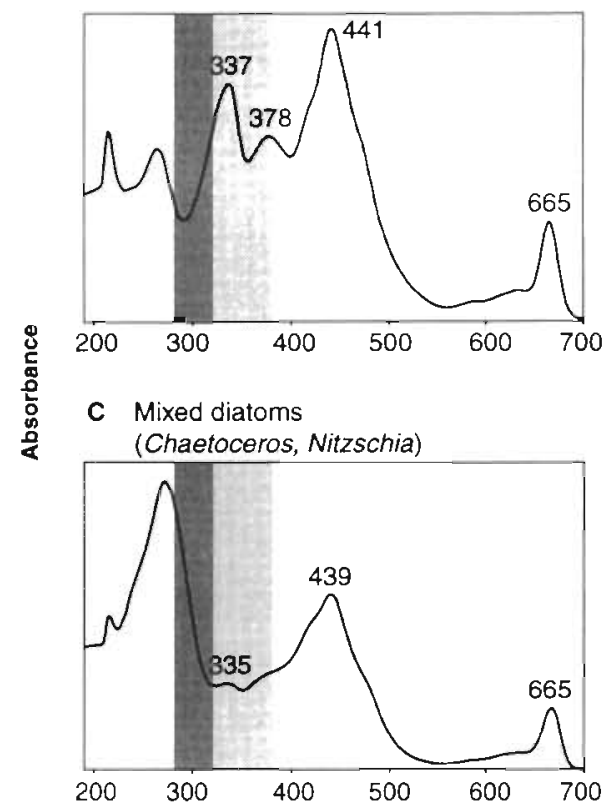

B Mixed dinoflagellates (Ceratium, Dinophysis)

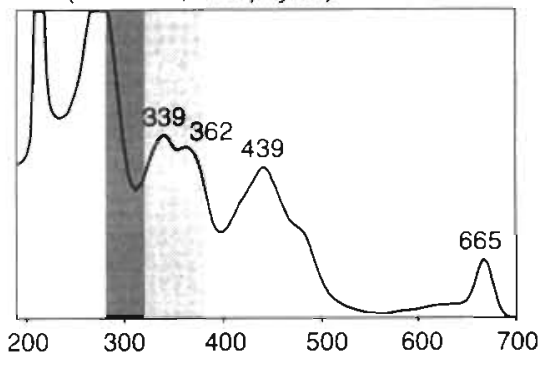

D Mixed diatoms and dinoflagellates (Coscinodiscus, Dinophysis)

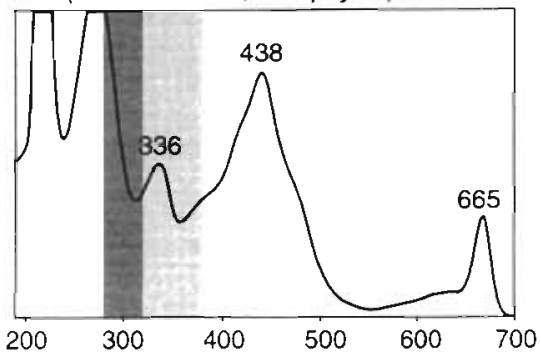

A Chaetoceros affinis CS-78

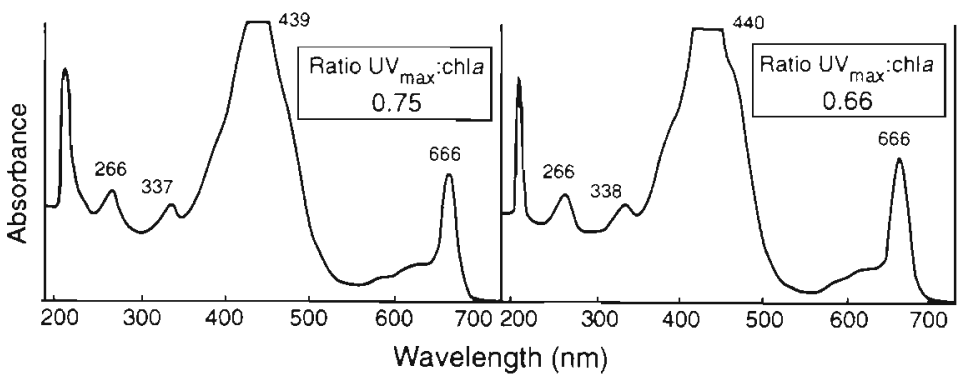

C Fibrocapsasp. CS-220

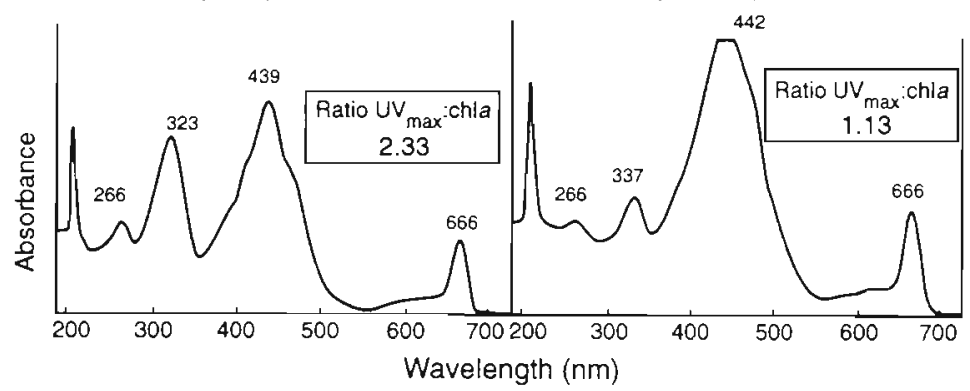

$\mathrm{E}$ Gymnodinium catenatum CS-309/3

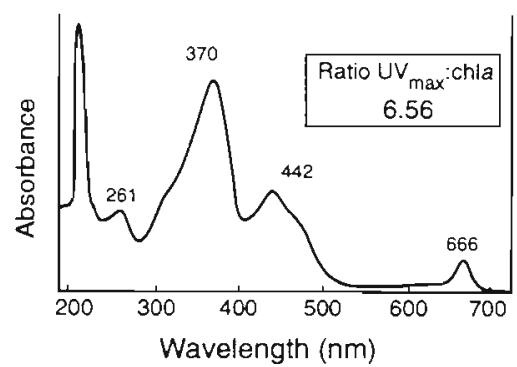

able yield-mycosporine-glycine, porphyra334 and shinorine. The major peak (retention time $\sim 9.4 \mathrm{~min}$ ) was an unknown compound, which occurred together with several unknown minor fractions. The major UV-absorbing component responsible for the large $370 \mathrm{~nm}$ absorption peak in the extract of G. catenatum (Fig. 4E) was not detected by this method of HPLC analysis (detection was at 313 and $340 \mathrm{~nm}$, see Fig. 5), and may not be an MAA compound.

The relative proportions of MAAs analyzed in each of the 5 selected species are given in Table 4. Concentrations per unit cell were not determined; concentrations per unit chlorophyll could not be assessed because the extinction coefficients of chlorophylls $a$ and $c$ in the extraction solvent had not been determined (tetrahydrofuran:methanol $=20: 80, v / v$, see Jeffrey \& Welschmeyer 1997). The most noteworthy features are the dominance of porphyra-334 and mycosporine-glycine in Fibrocapsa sp. (with palythine and asterina-330 minor components), the dominance of porphyra334 and shinorine in Woloszynskia sp., and

Fig. 4. UV-visible absorption spectra of tetrahydrofuran:methanol (20:80, v/v) extracts of 5 microalgal cultures used for HPLC analysis of microsporine-like amino acids (MAAs). (A) Chaetoceros affinis, CS-78 (diatom); (B) Heterosigma carterae, CS-169 (raphidophyte); (C) Fibrocapsa sp., CS-220 (raphidophyte); (D) Woloszynskia sp., CS-341 (dinoflagellate); (E) Gymnodinium catenatum, CS-309/3 (dinoflagellate) 


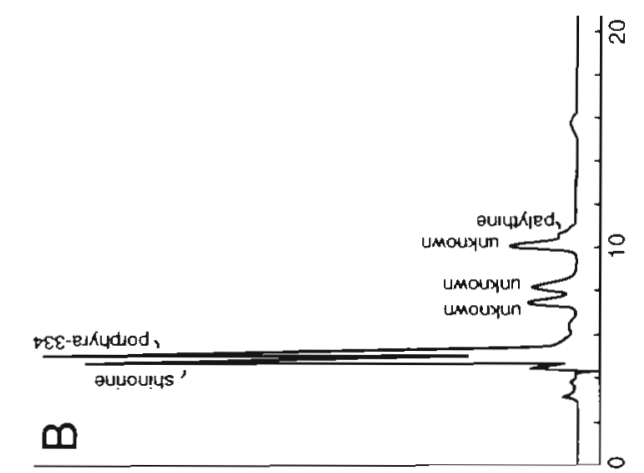

(uน 0 ०) әอчequosq

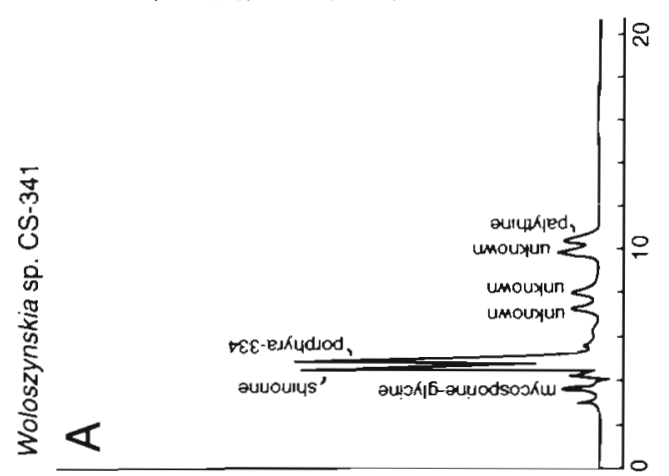

(wu $\varepsilon\llcorner\varepsilon$ ) əวuequosq

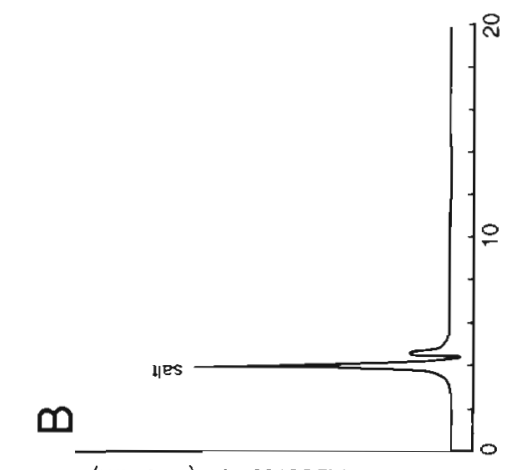

(wu ote) əouequosa

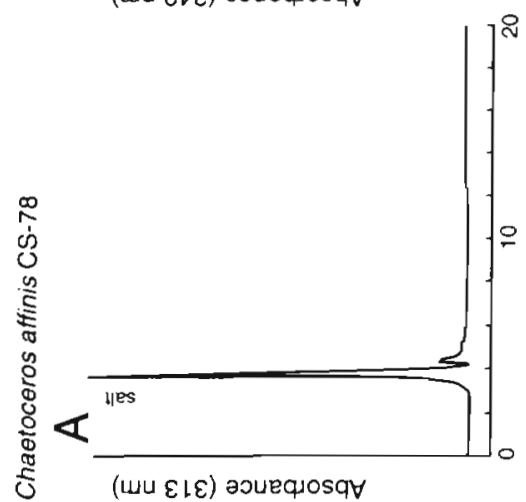

$\infty$

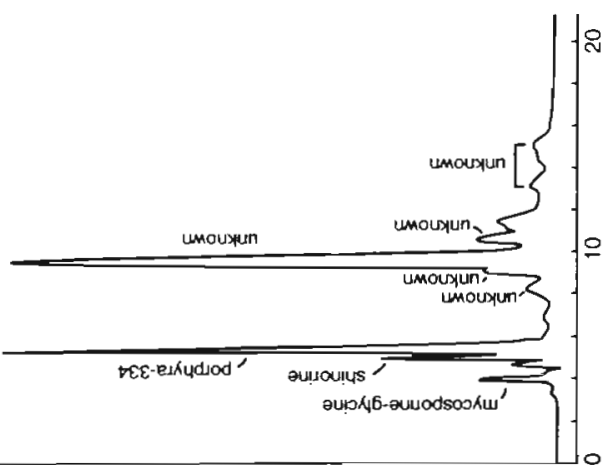

(wu $0 \downarrow \varepsilon$ ) əouequosq

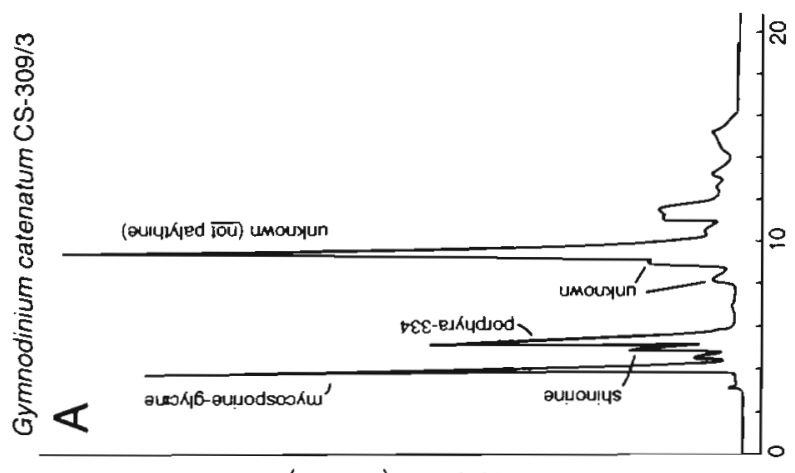

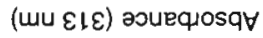

$\infty$ 它完

vo

का के ले

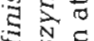

iิ $\frac{0}{0}$

03

过

它这

c $\tilde{U} \cup$

E 0 is

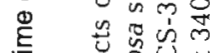

\% $0=$

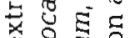

동

is 证过

$\$ 8 \pi$

$\sum \rightarrow \stackrel{0}{1}$

o

क व

(⿻)

疍

임

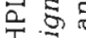

ज जे

का ब

事焉的 
Table 4. Relative proportions of mycosporine-like amino acids (MAAs) in quadruplicate analyses of tetrahydrofuran:methanol $(20: 80, v / v)$ extracts of 5 cultures of microalgae

\begin{tabular}{|c|c|c|c|c|c|c|c|}
\hline \multirow[t]{2}{*}{ Species } & \multirow{2}{*}{$\begin{array}{l}\text { CSIRO culture } \\
\text { code }\end{array}$} & \multicolumn{6}{|c|}{ MAAs (nmol ml ${ }^{-1}$ extract) ${ }^{d}$} \\
\hline & & $\begin{array}{l}\text { Mycosporine } \\
\text {-glycine }\end{array}$ & Shinorine & Porphyra-334 & Palythine & Asterina -330 & $\begin{array}{l}\text { Unknown MAA } \\
\text { (RT }-9.4 \mathrm{~min})\end{array}$ \\
\hline Chaetoceros affinis & $\mathrm{CS}-78$ & - & - & - & - & - & - \\
\hline Heterosigma carterae & CS -169 & - & $0.76 \pm 0.42$ & - & - & $1.54 \pm 0.04$ & - \\
\hline Fibrocapsa sp. & CS-220 & $74.86 \pm 1.20$ & - & $156.66 \pm 4.77$ & $1.23 \pm 0.89$ & $1.31 \pm 0.16$ & - \\
\hline Woloszynskia sp. & CS-341 & $2.34 \pm 0.79$ & $18.51 \pm 0.45$ & $23.78 \pm 0.99$ & $4.11 \pm 0.35$ & - & - \\
\hline $\begin{array}{l}\text { Gymnodinium } \\
\text { catenatum }\end{array}$ & CS-309/3 & $37.11 \pm 1.01$ & $7.36 \pm 1.25$ & $31.42 \pm 3.35$ & - & - & $\begin{array}{l}\text { Major component } \\
\text { (not quantified) }\end{array}$ \\
\hline
\end{tabular}

a major unidentified MAA in Gymnodinium catenatum, which co-occurred with lesser amounts of mycosporine-glycine, porphyra-334 and shinorine.

\section{DISCUSSION}

The 206 strains of cultured marine microalgae examined from 12 classes showed a wide variation in the dis. tribution of putative UV-screening pigments as grown under visible light conditions. The UV-screening capacity was judged on the basis of ratios of UVabsorbance (maxima 280 to $390 \mathrm{~nm}$ ) to $\mathrm{chl}$ a absorbance $(665 \mathrm{~nm})$ in extracts of algal cells grown without supplementary UV radiation (see Table 1 \& Fig. 2). The highest UV-screening capacity in both cultured microalgae and phytoplankton field samples was found in surface bloom-forming species of dinoflagellates, particularly strains of Gymnodinium catenatum, Alexandrium, Heterocapsa, Scrippsiella and Woloszynskia (see Table 3). Other bloom-forming flagellates had less, but still significant, UV-absorbing potential: the prymnesiophytes Chrysochromulina, Emiliania, Imantonia and Phaeocystis, the cryptomonads Chroomonas, Rhodomonas (including several unidentified strains), and the raphidophytes Chattonella and Fibrocapsa. Other algal classes showed UV:chl a absorbance ratios of less than 0.9 (see Table $1 \&$ Fig. 2): they included diatoms, chlorophytes, chrysophytes, eustigmatophytes, planktonic cyanophytes, prasinophytes, 1 euglenophyte and 1 rhodophyte.

The small spectral differences in Fibrocapsa sp. in Fig $1 \mathrm{~B}$ and a later culture used for HPLC analysis (Fig. 4C) could have been due to slightly different growth conditions or harvest times. The cause of small variations in absorption characteristics of individual strains were not studied here.

Because some of our microalgae were cultured for many years in the absence of supplementary UV radiation (see CSIRO 1998) the UV:chl a absorbance ratios should be considered the minimum achievable for the strains examined (Table 1). There is good evidence from the literature that UVA and/or UVB radiation can stimulate MAA synthesis in some microalgae: e.g. cyanobacteria (Garcia-Pichel \& Castenholz 1993), Antarctic marine diatoms (Helbling et al. 1996), Phaeocystis antarctica (Riegger \& Robinson 1997) and natural Antarctic phytoplankton field samples (Villafañe et al. 1995). Future work needs to examine if supplementary UV and blue radiation ( 370 to $460 \mathrm{~nm}$ ) during growth can induce synthesis of UV-absorbing compounds in cultured microalgae across the algal classes, as it does for MAAs in some cultured Antarctic marine diatoms (Riegger \& Robinson 1997). It is also necessary to examine whether algal species capable of MAA synthesis under conditions of visible light exposure alone may have an adaptive advantage, given the greater penetration of light of increasing wavelengths, for competitive survival of these species within a well-mixed photic zone.

Our HPLC analyses of MAAs in 2 cultures with low UV:chl a absorbance ratios (Chaetoceros affinis [0.75] and Heterosigma carterae [0.66]) while showing no MAAs in C. affinis, clearly showed the presence of small amounts of shinorine and asterina-330 in $H$. carterae. The lack of MAA peaks on the HPLC trace for C. affinis, which showed a small spectrophotometric peak at $337 \mathrm{~nm}$ in Fig. $4 \mathrm{~A}$, may have been due to the very low signal to noise ratio in the HPLC response. If MAA-like or other unidentified compounds are indeed present in algal species showing low UV:chl a absorbance ratios, then the capacity for their synthesis might be more widely distributed across algal classes than this study would suggest, needing only an external environmental trigger, such as UV or blue radiation exposure, for activation. These radiation effects may be even more complex, since UVA can inhibit photosynthesis in mixed assemblages of Antarctic phytoplankton (Holm-Hansen 1997), whereas UVA also reduces the effects of UVB inhibition in Antarctic cyanobacteria (Quesada et al. 1995). 
While the range of species examined for the occurrence of MAAs by HPLC was small (5 species from 3 algal classes), the results showed suites of MAAs clearly evident in species with moderate to high UV:chl a absorbance ratios: Fibrocapsa sp. (UV:chl a $=2.33$, porphyra-334, mycosporine-glycine, palythine and asterina), Woloszynskia sp. (UV:chl a = 1.13, porphyra-334, shinorine, palythine and mycosporine-glycine) and Gymnodinium catenatum (UV:chl $a=6.56$, major and minor unknown MAAs, plus mycosporine-glycine, porphyra-334 and shinorine).

Gymnodinium catenatum consistently showed UV absorption by spectrophotometry at 370 to 372,377 to $378 \mathrm{~nm}$ (see Figs. $1 \mathrm{H}, \mathrm{I}, \mathrm{J}, 3 \mathrm{~A} \& 4 \mathrm{E}$, respectively). This absorption does not match that of any known MAA, and may be due to a new MAA derivative with extended conjugation, a new class of UV-absorbing compounds or perhaps the cis-peak of a carotenoid. Further work is needed to secure the identification of the $G$. catenatum unknowns.

On the basis of these limited results it is expected that most microalgae with moderate to high UV:chl a absorbance ratios would be likely to contain significant amounts of MAAs, and good correlation between UV absorption recorded by spectrophotometry and MAA content determined by HPLC analysis has previously been observed (Dunlap et al. 1995). Indeed, the presence of unknown MAAs, as well as compounds absorbing in the near UVA region $(370$ to $378 \mathrm{~nm}$, see Fig. 4E, Gymnodinium catenatum) may indicate a rich source of new UV-absorbing compounds in dinoflagellates. These MAAs and related compounds may well act as effective UV screens to ensure the success of surface bloom-forming species in UV-rich environments.

Natural phytoplankton field samples obtained locally also showed high UV:chl a absorbance values for dinoflagellate-rich samples, and lower values when diatoms predominated. A natural bloom of Gymnodinium catenatum (Fig. 3A) showed absorption characteristics similar to those of 1 local strain maintained in culture (Fig. $1 \mathrm{H}$ ), but differed from 2 other $G$. catenatum strains (Fig. 11, J). Strain differences were a characteristic of species examined in this study (see Table 3 ).

The present investigation adds to the body of work provided by other authors (e.g. Vernet et al. 1989, Carreto et al. 1990, Helbling et al. 1996, Riegger \& Robinson 1997) to document the distribution of UV-protective pigments in microalgae. Our screen of 152 microalgal species (206 strains) showed that most algal classes had representatives with both low and high UV-absorptive capacity (Table 2). Bloom-forming species, especially dinoflagellates, were particularly enriched, and our study of Fibrocapsa sp. (raphidophyte), Woloszynskia sp. (dinoflagellate) and Gymnodinium catenatum (dinoflagellate) bear similarities to the results of Carreto et al. (1990), These authors reported a suite of MAAs in the red-tide dinoflagellate Alexandrium excavatum, whose UV-absorbing compounds spanned an absorption range from 310 to $360 \mathrm{~nm}$, to include MAAs with absorption at $310 \mathrm{~nm}$ (mycosporine glycine), $320 \mathrm{~nm}$ (palythine), $330 \mathrm{~nm}$ (asterina-330), $332 \mathrm{~nm}$ (palythinol), $334 \mathrm{~nm}$ (shinorine, porphyra-334), $337 \mathrm{~nm}$ (pathythenic acid), 357 (cis-usujirene) and $360 \mathrm{~nm}$ (palythene). These screening compounds would be expected to give broad cover from UVB (280 to $320 \mathrm{~nm}$ ) and UVA (320 to $380 \mathrm{~nm}$ ) radiation.

The successful bloom-forming dinoflagellate Gymnodinium catenatum contained previously known MAAs (mycosporine-glycine, porphyra-334 and shinorine) together with unidentified UV-absorbing components in the UVB (280 to $320 \mathrm{~nm}$ ), UVA (320 to $360 \mathrm{~nm}$ ) and the near UVA (>360 $\mathrm{nm}$ ) regions (see Figs. $4 \mathrm{E} \& 5$ ). The value of both spectrophotometric and HPLC techniques used in the present work is clearly seen, since the former picks up most UV-absorbing compounds, and the latter, as currently used, identifies known MAAs. Unidentified UV-absorbing components as found in $G$. catenatum will need further analytical study (eg. nuclear magnetic resonance/mass spectrometry) to secure identification.

It is clear from this survey that certain bloom-forming microalgae are 'sun-adapted' and have the capacity to synthesize sunscreen pigments whose chemistry, stimulation of biosynthesis by light of particular wavelengths and protective function warrant further investigation. While the most recent evidence shows a global levelling off of ozone-depleting emissions (Houghton 1996), indicating that the Montreal Protocol is beginning to work, the ozone hole over Antarctica formed in 1998 is the largest ever recorded (Soloman 1998). A heightened global UV flux is forecast to continue for several decades (Van der Leun et al. 1998), and could alter the biomass and floristic composition of marine phytoplankton species in certain habitats to favour those surface bloom-forming species most adapted to UV stress. Further study should determine whether this is a permanent or reversible threat to particular marine ecosystems.

Acknowledgements. We thank Ms Jeannie-Marie LeRoi for assistance with algal culturing. Dr H.S. MacTavish and Ms K. Groenewoud were supported by an ARC grant to Drs $M$. Vesk and $S$. W. Jeffrey for studies on UVB effects in marine microalgae

\section{LITERATURE CITED}

Adams NL, Shick JM (1996) Mycosporine-like amino acids provide protection against ultraviolet radiation in eggs of the green sea urchin Strongylocentrotus droebachiensis Photochem Photobiol 64:149-158 
Balch WM, Haxo FT (1984) Spectral properties of Noctiluca miliaris Suriray, a heterotrophic dinoflagellate. J Plankton Res 6:515-525

Behrenfeld MJ, Lee H, Small LF (1994) Interactions between nutritional status and long term responses to ultraviolet- $B$ radiation stress in a diatom. Mar Biol 118:523-530

Bornman JF (1989) New trends in photobiology: target sites of UV-B radiation in photosynthesis of higher plants. J Photochem Photobiol B Biol 4:145-158

Bornman JF, Teramura AH (1993) Effects of ultraviolet-B radiation on terrestrial vegetation. In: Young $A R, B j o r n ~ L O$, Moan J, Nultsch W (eds) Environmental UV photobiology Plenum Press, New York, p 427-471

Buma AGJ, van Hannen EJ, Roza L, Veldhuis MJW, Gieskes WWC (1995) Monitoring ultraviolet-B-induced DNA dam. age in individual diatom cells by immunofluorescent thymine dimer detection. J Phycol 31:314-321

Buma AGJ, van Hannen EJ, Veldhuis MJW, Gieskes WWC (1996) UV-B induces DNA damage and DNA synthesis delay in the marine diatom Cyclotella sp. Sci Mar 60(Suppl 1):101-106

Caldwell MM (1981) Plant responses to solar ultraviolet radiation. In: Lange $\mathrm{OL}$, Nobel PS, Osmund $\mathrm{CB}$, Ziegler $\mathrm{H}$ (eds) Physiological Plant Ecology. I. Responses to the physical environment. Encyclopedia of plant physiology, New Series, Vol 12A. Springer Verlag, New York, p $169-198$

Calkins $J$ (1982) The role of solar ultraviolet radiation in marine ecosystems. Plenum Press, New York

Carreto JI, Carignan MO, Daleo G, de Marco SG (1990) Occurrence of mycosporine-like amino acids in the redtide dinoflagellate Alexandrium excavatum: UV-photoprotective compounds? J Plankton Res 12:909-921

Carroll AK, Shick JM (1996) Dietary accumulation of UVabsorbing mycosporine-like amino acids (MAAs) by the green sea urchin (Stronglocentrotus droebachiensis). Mar Biol 124:561-569

Chalker BE, Dunlap WC (1982) Extraction and quantitation of endosymbiotic algal pigments from reef-building corals. In: Gomez ID et al. (eds) Proc 4th Int Coral Reefs Symp. Vol 2. Marine Sciences Center, University of the Philipines, Manila, p 45-50

CSIRO (1998) Collection of living microalgae: strain list. Report obtainable from senior author

Dionisio-Sese ML, Ishikura M, Marayama T, Miyachi S (1997) UV-absorbing substances in the tunic of a colonial ascidian protect its symbiont, Prochloron sp. from damage by UV-B radiation. Mar Biol 128:455-461

Döhler G (1996) Effect of UV irradiance on utilization of inorganic nitrogen by the Antarctic diatom Odontella weissflogii (Janisch) Grunow. Bot Acta 109:35-42

Döhler G, Worrest RC, Biermann I, Zink J (1987) Photosynthetic ${ }^{14} \mathrm{CO}_{2}$ fixation and ${ }^{15} \mathrm{~N}$-ammonia assimilation during UV-B radiation of Lithodesmium variabile. Physiol Plant 70:511-515

Döhler G, Hagmeier E, Grigoleit E, Krause KD (1991) Impact of solar UV radiation on uptake of ${ }^{15} \mathrm{~N}$-ammonia and ${ }^{15} \mathrm{~N}$ nitrate by marine diatoms and natural phytoplankton. Biochem Physiol Pflanz (BPP) 187:293-303

Donkor VA, Amewowor DHAK, Häder DP (1993) Effects of tropical solar radiation on the velocity and photophobic behaviour of filamentous gliding cyanobacteria. Acta Protozool 32:67-72

Dunlap WC, Chalker BE (1986) Identification and quantitation of near-UV absorbing compounds (S-320) in a reefbuilding coral. Coral Reefs 5:155-159

Dunlap WC, Shick JM (1998) Ultraviolet-radiation-absorbing mycosporine-like amino acids in coral reef organisms: a biochemical and environmental perspective. J Phycol 34 : $418-430$

Dunlap WC, Yamamoto Y (1995) Small molecule antioxidants in marine organisms: antioxidant activity of mycosporineglycine. Comp Biochem Physiol 112B:105-114

Dunlap WC, Chalker BE, Oliver JK (1986) Bathymetric adaptations of reef-building corals at Davies Reef, Great Barrier Reef, Australia. III. UV-B absorbing compounds. J Exp Mar Biol Ecol 104:239-248

Dunlap WC, Williams D McB, Chalker BE, Banaszak AT (1989) Biochemical photoadaptation in vision: UV-absorbing pigments in fish eye tissues. Comp Biochem Physiol 93B:601-607

Dunlap WC, Rae GA, Helbling EW, Villafane VE, HolmHansen $O$ (1995) Ultraviolet-absorbing compounds in natural assemblages of antarctic phytoplankton. Antarct $J$ US 30:323-326

Ekelund NGA (1990) Effects of UV-B radiation on growth and mortality of four phytoplankton species. Physiol Plant 78 $590-594$

El-Sayed SZ, Stephens FC (1992) Potential effects of increased ultraviolet radiation on the productivity of the Southern Ocean. In: Dunerette DA, O'Brien RJ (eds) The science of global change: the impact of human activities on the environment. Am Chem Soc Symp Ser 483, Washington, DC, p 188-206

Farman JC, Gardiner BG, Shanklin JD (1985) Large losses of total ozone in Antarctica reveal seasonal $\mathrm{ClO}_{\mathrm{x}} / \mathrm{NO}_{\mathrm{x}}$ interaction. Nature (Lond) 315:207-210

Frederick JE, Snell HE (1988) Ultraviolet radiation levels during the Antarctic Spring. Science 241:438-440

Garcia-Pichel F, Castenholz RW (1991) Characterization and biological implications of scytonemin, a cyanobacterial sheath pigment. J Phycol 27:395-409

Garcia-Pichel F, Castenholz RW (1993) Occurrence of UVabsorbing, mycosporine-like compounds among cyanobacterial isolates and an estimate of their screening capacity. Appl Environ Microbiol 59:163-169

Goes JI, Handa N, Taguchi S, Hama T (1995) Changes in the patterns of biosynthesis and composition of amino acids in a marine phytoplankter exposed to ultraviolet- $\mathrm{B}$ radiation nitrogen limitation implicated. Photochem Photobiol 62 $703-710$

Guillard RRL, Ryther JH (1962) Studies of marine plankton diatoms. I. Cyclotella nana Hustedt and Detonula confervacea (Cleve) Gran. Can J Microbiol 8:229-239

Häder DP. Häder MA (1988) Inhibition of motility and phototaxis in the green flagellate Euglena gracilis by UV-B radiation. Arch Microbiol 150:20-25

Halldal P (1967) Ultraviolet action spectra in algology: a review. Photochem Photobiol 6:445-460

Hallegraeff GM, Stanley SO, Bolch CJ, Blackburn SI (1989) Gymnodinium catenatum blooms and shellfish toxicity in southern Tasmania, Australia. In: Okaichi T, Anderson DM, Nemoto $T$ (eds) Red tides: biology, environmental science and toxicology. Elsevier Publishing, New York, p 77-80

Helbling EW, Chalker BE, Dunlap WC, Holm-Hansen E, Villafañe VE (1996) Photoacclimation of antarctic marine diatoms to solar ultraviolet radiation. J Exp Mar Biol Ecol 204:85-101

Holm-Hansen O (1997) Short- and long-term effects of UVA and UVB on marine phytoplankton productivity. Photochem Photobiol 65:266-269

Houghton JT (1996) Report of Working Group 1 of the Intergovernmental Panel on Climate Change. Cambridge University Press 
Jeffrey SW (1980) Cultivating unicellular marine plants. In: Fisheries and oceanography annual reports 1977-1979. CSIRO, Hobart, Tasmania, p 22-43

Jeffrey SW, LeRoi JM (1997) Simple procedures for growing SCOR reference microalgal cultures. In: Jeffrey SW, Mantoura RFC, Wright SW (eds) Phytoplankton pigments in oceanography: guidelines to modern methods. UNESCO Publishing, Paris, p 181-205

Jeffrey SW, Vesk M (1976) Further evidence for a membranebound endosymbiont within the dinoflagellate Peridinium foliaceum. J Phycol 12:450-455

Jeffrey SW, Welschmeyer NA (1997) Spectrophotometric and fluorometric equations in common use in oceanography. In: Jeffrey SW, Mantoura RFC, Wright SW (eds) Phytoplankton pigments in oceanography: guidelines to modern methods. UNESCO Publishing, Paris, p 597-615

Jeffrey SW, Sielicki $M$, Haxo FT (1975) Chloroplast pigment patterns in dinoflagellates. J Phycol 11:374-384

Jerlov NG (1950) Ultraviolet radiation in the sea. Nature (Lond) 116:111-112

Jerlov NG (1976) Marine optics. Elsevier, New York

Jitts HR, Morel A, Saijo Y (1976) The relation of oceanic primary production to available photosynthetic irradiance. Aust J Mar Freshw Res 27:441-454

Jordan BR, Chow WS, Strid A, Anderson JM (1991) Reduction in $c a b$ and psb A RNA transcripts in response to supplementary ultraviolet-B radiation. FEBS Lett 284:5-8

Karentz D, Cleaver JE, Mitchell DL (1991a) Cell survival characteristics and molecular responses of Antarctic phytoplankton to ultraviolet-B radiation. J Phycol 27:326-341

Karentz D, McEuen FS, Land MC, Dunlap WC (1991b) Survey of mycosporine-like amino acid compounds in Antarctic marine organisms: potential protection from ultraviolet exposure. Mar Biol 108:157-166

Karsten U, Garcia-Pichel F (1996) Carotenoids and mycosporine-like amino acid compounds in members of the genus Microcoleus (cyanobacteria): a chemosystemaic study. Syst Appl Microbiol 19:285-294

Keller MD, Selvin RC, Claus W, Guillard RRL (1987) Media for the culture of oceanic ultraphytoplankton. J Phycol 23: 633-638

Kerr JB, McElroy CT (1993) Evidence for large upward trends of ultraviolet-B radiation linked to ozone depletion. Science 262:1032-1034

Lesser MP (1996) Acclimation of phytoplankton to UV-B radiation: oxidative stress and photoinhibition of photosynthesis are not prevented by UV-absorbing compounds in the dinoflagellate Prorocentrum micans. Mar Ecol Prog Ser 132:287-297

Lesser MP, Cullen JJ, Neale PJ (1994) Carbon uptake in a marine diatom during acute exposure to ultraviolet $\mathrm{B}$ radiation: relative importance of damage and repair. J Phycol 30:183-192

Lesser MP, Neale PJ, Cullen JJ (1996) Acclimation of Antarctic phytoplankton to ultraviolet radiation: ultraviolet absorbing compounds and carbon fixation. Mol Mar Biol Biotechnol 5:314-325

Loeblich AR, Smith VE (1968) Chloroplast pigments of the marine dinoflagellate Gyrodinium resplendens. Lipids 3:5-13

Lorenzen CJ (1979) Ultraviolet radiation and phytoplankton photosynthesis. Limnol Oceanogr 24:1117-1120

Marchant HJ, Davidson AT, Kelly GJ (1991) UV-B protecting compounds in the marine alga Phaeocystis pouchetii from Antarctica. Mar Biol 109:391-395

Nakamura H, Kobayashi J, Hirata Y (1981) Isolation and structure of a $330 \mathrm{~nm}$ UV-absorbing substance, asterina-
330, from the starfish Asterina pectinifera. Chem Lett 1981:1413-1414

Nakamura H, Kobayashi J, Hirata Y (1982) Separation of mycosporine-like amino acids in marine organisms using reversed-phase high-performance liquid chromatography. J Chromatogr 250:113-118

Neale PJ, Banazak AT, Jarriel CR (1998) Ultraviolet sunscreens in Gymnodinium sanguineum (Dinophyceae): mycosporine-like amino acids protect against inhibition of photosynthesis. J Phycol 34:928-938

Nichols HW (1973) Growth media-freshwater. In: Stein JR (ed) Handbook of phycological methods: culture methods and growth measurements. Cambridge University Press, p 7-24

Nichols HW, Bold HC (1965) Trichosarcina polymorpha gen. et sp. nov. J Phycol 1:34-38

Nielsen T, Ekelund NGA (1993) Effect of UV-B radiation and humic substances on growth and motility of Gyrodinium aureolum. Limnol Oceanogr 37:1570-1575

Oren A (1997) Mycosponine-like amino acids as osmotic solutes in a community of halophilic cyanobacteria. Geomicrobiol J 14:231-240

Provasoli L, McLaughlin JJA, Droop MR (1957) The development of artificial media for marine algae. Arch Mikrobiol 25:392-428

Quesada A, Mouget JL, Vincent WF (1995) Growth of Antarctic cyanobacteria under ultraviolet radiation: UVA counteracts UVB inhibition. J Phycol 31:242-248

Riegger L, Robinson D (1997) Photoinduction of UV-absorbing compounds in Antarctic diatoms and Phaeocystis antarctica. Mar Ecol Prog Ser 160:13-25

Roy CR, Gies HP, Elliott G (1990) Ozone depletion. Nature (Lond) 347:235-236

Rozema J, Gieskes WWC, van de Geijn, Nolan C, de Boois H (1997) UV-B and the biosphere. Kluwer Academic Publications, Dordrecht

Sancar A, Sancar GB (1988) DNA repair enzymes. Ann Rev Biochem 57:29-67

Shibata K (1969) Pigments and a UV-absorbing substance in corals and a blue-green alga living in the Great Barrier Reef. Plant Cell Physiol 10:325-335

Shick JM, Lesser MP, Stochaj WR (1991) Ultraviolet radiation and photooxidative stress in zooxanthellate Anthozoa: the sea anemone Phyllodiscus semoni and the octocoral Clavularia sp. Symbiosis 10:145-173

Shick JM, Dunlap WC, Chalker BE, Banaszak AT, Rosenzweig TK (1992) Survey of ultraviolet radiation-absorbing mycosporine-like amino acids in organs of coral reef holothuroids. Mar Ecol Prog Ser 90:139-148

Shick JM, Lesser MP, Dunlap WC, Stochaj WR, Chalker BE, Wu Won J (1995) Depth-dependent responses to solar ultraviolet radiation and oxidative stress in the zooxanthellate coral Acropora microphthalma. Mar Biol 122:41-51

Smith RC, Baker KS, Holm-Hansen O, Olsen R (1980) Photoinhibition of photosynthesis in natural waters. Photochem Photobiol 31:585-592

Smith RC, Prezelin BB, Baker KS, Bidigare RR, Boucher NP, Coley T, Karentz D, MacIntyre S, Matlick HA, Menzies D. Ondrusek M, Wan Z, Waters KJ (1992) Ozone depletion: ultraviolet radiation and phytoplankton biology in Antarctic waters. Science 255:952-959

Soloman S (1998) Ozone depletion from pole to pole. Priestly Lecture, CSIRO Atmospheric Research, October 1, 1998, Melbourne, Australia

Steemann Nielsen $E$ (1964) On a complication in marine productivity work due to the influence of ultraviolet light. $\mathrm{J}$ Cons Int Explor Mer 29:130-135 
Stochaj WR, Dunlap WC, Shick JM (1994) Two new UVabsorbing mycosporine-like amino acids from the sea anemone Anthopleura elegantissima and the effects of zooxanthellae and spectral irradiance on chemical composition and content. Mar Biol 118:149-156

Stolarski R, Bojkov R, Bishop L, Zerefos C, Staehelin J, Zawodny J (1992) Measured trends in stratospheric ozone. Science 256:342-349

Strid A, Chow WS, Anderson JM (1990) Effects of supplementary ultraviolet-B radiation on photosynthesis in Pisum sativum. Biochim Biophys Acta 1020:260-268

Sundbäck K, Nilsson C, Odmark S, Wulff A (1996) Does ambient UV-B radiation influence marine diatom-dominated $\mathrm{mi}$ crobial mats? A case study. Aquat Microb Ecol 11:151-159

Sundbäck K, Odmark S, Wulff A, Nilsson C, Wängberg S $\AA$ (1997) Effects of enhanced UVB radiation on a marine benthic diatom mat. Mar Biol 128:171-179

Tomas RN, Cox ER (1973) The symbiosis of Peridinium balticum (Dinophyceae). I. Ultrastructure and pigment analysis. J Phycol 9(Suppl): 16

Tsujino I, Yabe K, Sekikawa I (1980) Isolation and structure of a new amino acid, shinorine, from the red alga Chondrus yendoi Yamada et Mikami. Bot Marr 23:65-68

Van der Leun JC, Tang X, Teuini M (eds) (1998) Environmental effects of ozone depletion: 1998 assessment. United Nations Environmental Programme, Nairobi

Editorial responsibility: Otto Kinne (Editor)

Oldendorf/Luhe, Germany
Vernet M, Neori A, Haxo FT (1989) Spectral properties and photosynthetic action in red-tide populations of Prorocentrum micans and Gonyaulax polyedra. Mar Biol 103: 365-371

Villafañe VE, Helbling EW, Holm-Hansen O, Chalker BE (1995) Acclimation of Antarctic natural phytoplankton assemblages when exposed to solar ultraviolet radiation. J Plankton Res 17:2295-2306

Wilson Ml, Ghosh S, Gerhardt KE, Holland N, Sudhakar Babu T. Edelman M, Dumbroff EB, Greenberg BM (1995) In vivo photomodification of ribulose-1,5-bisphosphate carboxylase/oxygenase holoenzyme by ultraviolet- $B$ radiation. Plant Physiol 109:221-229

Worrest RC (1982) Review of literature concerning the impact of UV-B radiation upon marine organisms. In: Calkins $J$ (ed) The role of solar ultraviolet radiation in marine ecosystems. Plenum Press, New York, p 429-457

Worrest RC, Häder DP (1997) Overview of the effects of increased solar UV on aquatic microorganisms. Photochem Photobiol 65:257-259

Worrest RC, Brooker DL, Van Dyke H (1980) Results of a primary productivity study as affected by the type of glass in the culture bottles. Limnol Oceanogr 25:360-364

Xiong F, Komenda J, Kopecky J, Nedbal L (1997) Strategies of ultraviolet- $B$ protection in microscopic algae. Physiol Plant $100: 378-388$

Submitted: December 21, 1998; Accepted: June 3, 1999 Proofs received from author(s): November 9, 1999 